\title{
The fate of saharan dust across the atlantic and implications for a central american dust barrier
}

\author{
E. Nowottnick ${ }^{1}$, P. Colarco ${ }^{2}$, A. da Silva ${ }^{3}$, D. Hlavka ${ }^{4}$, and M. McGill ${ }^{5}$ \\ ${ }^{1}$ Atmospheric and Oceanic Sciences, University of Maryland, College Park, MD, USA \\ ${ }^{2}$ Atmospheric Chemistry and Dynamics Branch, Code 613.3, NASA Goddard Space Flight Center, Greenbelt, MD, USA \\ ${ }^{3}$ Global Modeling and Assimilation Office, Code 610.1, NASA Goddard Space Flight Center, Greenbelt, MD, USA \\ ${ }^{4}$ Science Systems and Applications, Inc., Code 613.1, NASA Goddard Space Flight Center, Greenbelt, MD, USA \\ ${ }^{5}$ Mesoscale Atmospheric Process Branch, Code 613.1, NASA Goddard Space Flight Center, Greenbelt, MD, USA
}

Received: 19 February 2011 - Published in Atmos. Chem. Phys. Discuss.: 11 March 2011

Revised: 18 July 2011 - Accepted: 24 July 2011 - Published: 18 August 2011

\begin{abstract}
Saharan dust was observed over the Caribbean basin during the summer 2007 NASA Tropical Composition, Cloud, and Climate Coupling $\left(\mathrm{TC}^{4}\right)$ field experiment. Airborne Cloud Physics Lidar (CPL) and satellite observations from MODIS suggest a barrier to dust transport across Central America into the eastern Pacific. We use the NASA GEOS-5 atmospheric transport model with online aerosol tracers to perform simulations of the $\mathrm{TC}^{4}$ time period in order to understand the nature of this barrier. Our simulations are driven by the Modern Era Retrospective-Analysis for Research and Applications (MERRA) meteorological analyses. Compared to observations from MODIS and CALIOP, GEOS-5 reproduces the observed location and magnitude of observed dust events, but our baseline simulation does not develop as strong a barrier to dust transport across Central America as observations suggest. Analysis of the dust transport dynamics and loss processes suggest that while both mechanisms play a role in defining the dust transport barrier, loss processes by wet removal of dust are about twice as important as transport. Sensitivity analyses with our model showed that the dust barrier would not exist without convective scavenging over the Caribbean. The best agreement between our model and the observations was obtained when dust wet removal was parameterized to be more aggressive, treating the dust as we do hydrophilic aerosols.
\end{abstract}

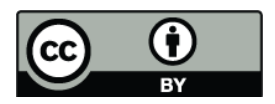

Correspondence to: E. Nowottnick (epnowott@atmos.umd.edu)

\section{Introduction}

During boreal summer, Saharan dust is transported to the Caribbean and northern South America by the prevailing tropical easterly winds (Karyampudi et al., 1999; Carlson and Prospero, 1972). Mineral dust aerosols influence Earth's radiation budget directly through the scattering and absorption of light (Zhu et al., 2007; Haywood et al., 2003; Sokolik and Toon, 1996) and indirectly by serving as cloud condensation nuclei (CCN) (Rosenfeld et al., 2001) and ice nuclei (DeMott et al., 2003) and so affecting the properties of clouds. Dust aerosols may modulate tropical cyclogenesis over the tropical North Atlantic by modifying wind fields during development and reducing sea surface temperatures through the absorption of short wave radiation (Lau and Kim, 2007; Dunion and Velden, 2004). Chemically, dust aerosols are comprised of both soluble and insoluble forms of iron. While the iron in dust aerosols is primarily insoluble, photochemical and cloud processing can convert it into a soluble form (Hand et al., 2004; Kieber et al., 2003; Desbouefs et al., 2001; Zhu et al., 1997). This has biogeochemical implications, as soluble iron in dust aerosols can serve as a nutrient source for aquatic and terrestrial ecosystems (Mahowald et al., 2005; Jickells et al., 2005; Falkowski et al., 2003).

Satellite observations show an apparent barrier to dust transport from the Caribbean into the eastern Pacific (Fig. 2). This barrier is also apparent in airborne observations from the recent NASA Tropical Composition Cloud and Climate Coupling $\left(\mathrm{TC}^{4}\right.$ ) field campaign (July-August 2007) (Toon et al., 2010). Modeling studies, on the other hand, suggest a large fraction of the dust loading and deposition in the eastern Pacific is Saharan in origin (e.g., Luo et al., 2003; Tanaka

Published by Copernicus Publications on behalf of the European Geosciences Union. 
and Chiba, 2005; Mahowald, 2007). The modeling results suggest a more permeable barrier to dust transport than the satellite observation indicate, but are inconsistent with the observed strong west-to-east gradient of decreasing dust deposition into the Pacific (Winckler et al., 2008). The presence of this barrier likely has geochemical implications, insofar as it inhibits transport of iron containing Saharan dust to aquatic and terrestrial ecosystems west of $80^{\circ} \mathrm{W}$.

While numerous studies have focused on the broader patterns of dust transport and deposition into the Caribbean (Kaufman et al., 2005; Mahowald et al., 1999, Tegen and Fung, 1995; Duce et al., 1991), we are not aware of any studies which have focused on the mechanisms for the observed barrier to dust transport into the Pacific and its representation in global dust transport models. We are uncertain as to the relative roles of dust removal and transport processes in establishing and maintaining this barrier. Furthermore, while dust removal processes such as precipitation scavenging certainly are important, there are insufficient data to fully constrain the representation of these processes in aerosol transport models. Perhaps better constrained are dynamical features, insofar as they are well represented in meteorological analyses, and we may ascertain the relative importance of meteorology in tracer transport studies.

We attempt such an investigation here by running an aerosol transport model driven by observed meteorology. We focus on dust transport during summer 2007 in order to exploit aircraft observations made during the NASA $\mathrm{TC}^{4}$ field campaign. The short time period covered in the present investigation is in part a reflection of the computational expense in carrying out high spatial resolution $(50 \mathrm{~km})$ global aerosol simulations, but we reach some tentative conclusions about the relative importance of removal and transport mechanisms in establishing this barrier and chart a path for future studies to follow. Section 2 describes the aerosol transport model and data sources employed. We present the Central American dust barrier in Sect. 3. We then explore the cause of the barrier by analyzing the dynamical and loss transport pathways of the dust in this region (Sect. 4). We additionally explore the sensitivity of our analyses to uncertainties in our parameterization of dust loss through wet processes (Sect. 5). We discuss our conclusions in Sect. 6.

\section{Model description and data sources}

In this section we introduce the NASA GEOS-5 aerosol transport model and observational data sources that show evidence of the Central American dust barrier and are used to evaluate dust transport in GEOS-5 during $\mathrm{TC}^{4}$.

\subsection{Model description}

Our aerosol transport model is based on the Goddard Earth Observing System (GEOS-5) model, the latest version of the
NASA Global Modeling and Assimilation Office (GMAO) earth system model. GEOS-5 contains components for atmospheric circulation and composition (including atmospheric data assimilation), ocean circulation and biogeochemistry, and land surface processes. Components and individual parameterizations within components are coupled under the Earth System Modeling Framework (ESMF) (Hill et al., 2004). The GEOS-5 earth system model serves as a stateof-the-art modeling tool for studying climate variability and change, and provides research quality reanalyses for use by NASA instrument teams and the scientific community. In addition to traditional meteorological parameters (winds, temperatures, etc.) (Rienecker et al., 2008), GEOS-5 includes modules representing the atmospheric composition, notably aerosols (Colarco et al., 2010) and tropospheric/stratospheric chemical constituents (Pawson et al., 2008), and includes the impact of these constituents on radiative processes within the atmosphere.

GEOS-5 has the capability to run at various horizontal spatial resolutions, from $4^{\circ} \times 5^{\circ}$ latitude by longitude for long climate integrations to $\sim 3 \times 3 \mathrm{~km}^{2}$ using advanced dynamical cores. The version we use here is run at $0.5^{\circ} \times 0.625^{\circ}$ latitude by longitude, to match the spatial resolution of the meteorological analyses used to drive our simulations. The model has 72 vertical layers distributed in a hybrid coordinate system that is terrain following near the surface and transforms to pressure coordinates near $180 \mathrm{hPa}$, with a model top at about $85 \mathrm{~km}$.

GEOS- 5 can be run as a climate model or as a data assimilation system. In both modes, the model makes a forecast of meteorology and tracer distributions from a set of initial conditions. In the data assimilation mode, a meteorological analysis is performed at specified intervals (typically every six hours). The analysis established the meteorological initial conditions for the next forecast cycle. In this study we exploit the GEOS-5 capability to "replay" from a prior data assimilation run. Rather than formally running the data assimilation system, we replace the model's meteorological state with the state from a pervious data assimilation run. This is functionally similar to hindcast simulations performed in offline chemical transport models (CTMs) in that meteorological analyses are used to drive the model for a specified period of time. The difference is that in offline CTMs the meteorological state is typically interpolated between the analysis time steps, whereas in GEOS-5 we are making a selfconsistent forecast during this period. Here we replay from the Modern Era Retrospective Analysis for Research and Applications (MERRA) (Rienecker et al., 2011) dataset, available every six hours at a spatial resolution of $0.5^{\circ} \times 0.625^{\circ}$ latitude by longitude.

The aerosol module in GEOS-5 is based on the Goddard Chemistry, Aerosol, Radiation, and Transport (GOCART) model (Chin et al., 2002), as previously integrated into an earlier version of the GEOS model framework (Colarco et al., 2010). GOCART provides a treatment of five tropospheric 
aerosol species (dust, sea salt, black carbon, organic carbon, and sulfate), including their sources, sinks, and chemistry. Our treatment of dust follows from GOCART and the description given in Nowottnick et al. (2010). The dust size distribution is partitioned into five non-interacting size bins spaced between 0.1 and $10 \mu \mathrm{m}$ radius. Dust mobilization follows from Ginoux et al. (2001) with sources preferentially located in large-scale topographic depressions (see also Prospero et al., 2002). Dust losses are through dry and wet removal processes, including turbulent dry deposition, sedimentation, and wet removal by large-scale and convective cloud systems. Further details of our treatment of dust, including dust optics, are provided in Nowottnick et al. (2010) and Colarco et al. (2010).

\subsection{Data sources}

\subsubsection{MODIS}

The Moderate Resolution Imaging Spectroradiometer (MODIS) was launched on 12 December 1999 aboard the Terra spacecraft. A second MODIS instrument was launched on the Aqua satellite as a part of the NASA A-Train on 4 May 2002. The MODIS instruments provide multispectral observations of the Earth system using 36 channels at 10:30 a.m. (Terra) and 01:30 p.m. (Aqua) local time. MODIS aerosol retrievals are made at a spatial resolution of at $10 \times 10 \mathrm{~km}^{2}$ using separate retrieval algorithms for ocean and land. Over oceans, the MODIS algorithm uses retrieved radiances from six channels $(550,660,870,1240,1630$, and $2130 \mathrm{~nm}$ ) to provide aerosol information at seven wavelengths, using the six retrieved channels and an additional fitted wavelength at $470 \mathrm{~nm}$ (Remer et al., 2005). Over land, an empirical relationship between radiance retrievals at two visible channels (470 and $660 \mathrm{~nm}$ ) and one near-IR channel $(2130 \mathrm{~nm})$ is used to determine the surface reflectivity to provide aerosols properties at 470, 550, and $660 \mathrm{~nm}$ (Remer et al., 2005). For our analysis, we use MODIS aerosol optical thickness (AOT) observations at $550 \mathrm{~nm}$ from collection 5.1. MODIS provides semi-quantitative quality assurance (QA) flags, where QA ranges in integer from $\mathrm{QA}=0$ (low confidence in aerosol retrieval) to $\mathrm{QA}=3$ (high confidence in retrieval). Over land we aggregate only highest quality $(\mathrm{QA}=3)$ retrievals, whereas over ocean we aggregate all retrievals but weight them by their respective QA flag value, similar to the MODIS canonical Level 3 gridded product (Levy et al., 2009).

\subsubsection{CALIOP}

The Cloud-Aerosol Lidar with Orthogonal Polarization (CALIOP) was launched onboard CALIPSO on 28 April 2006 as part of the NASA A-Train. CALIOP is a twochannel (532 and $1064 \mathrm{~nm}$ ) spaceborne lidar that provides profiles of cloud and aerosol properties along the satellite subpoint (Vaughan, 2005). CALIOP has a temporal resolution of $20.16 \mathrm{~Hz}$ and vertical resolution that varies from $30 \mathrm{~m}$ in the troposphere up to $60 \mathrm{~m}$ at higher altitudes. Because CALIOP is an active instrument, it provides both a daytime (01:30 p.m. local time) and nighttime (01:30 a.m. local time) measurement. CALIOP sends out polarized light at $532 \mathrm{~nm}$ and is equipped with sensors that measure the parallel and perpendicular components of the backscattered signal. The standard CALIOP retrieval provides measurements of total attenuated backscatter at each channel (Vaughan, 2005). However, polarization information and spectral variation of the backscatter can be used to infer the presence of aerosols and their type (Vaughan, 2005) In the CALIOP algorithm, backscatter from aerosols is differentiated from clouds by defining a lidar color ratio $\left(\beta_{1064 \mathrm{~nm}} / \beta_{532 \mathrm{~nm}}\right)$. At visible wavelengths, aerosols exhibit spectral variation while clouds do not, therefore a lidar color ratio that is approximately one is used to identify clouds (Vaughan, 2005). Once aerosols are differentiated from clouds, polarization properties can be used to infer aerosol type. Non-spherical aerosols such as dust are depolarizing and contribute to signal return in both the perpendicular and parallel planes. Spherical aerosols are not strongly polarizing and scatter predominantly in the parallel plane. Therefore, a depolarization ratio ( $\beta_{\text {perpendicular }} / \beta_{\text {parallel }}$ ) can be defined to identify the presence of non-spherical aerosols. For our analysis, we use CALIOP version 3.01 data, which offers an improved technique for the daytime $532 \mathrm{~nm}$ total attenuated backscatter calibration relative to previous versions.

\subsubsection{CPL}

The Cloud Physics Lidar (CPL) is a multi-pulse lidar that has provided observations during several NASA field campaigns (McGill et al., 2004, 2000). During TC ${ }^{4}$, CPL flew on the NASA ER-2 aircraft, providing profiles of total attenuated backscatter on 16 different days. CPL measures backscatter at 3 wavelengths $(355,532$, and $1064 \mathrm{~nm})$ with a frequency of $5 \mathrm{kHz}$ and depolarization ratio at $1064 \mathrm{~nm}$ (McGill et al., 2002). Processed CPL data is available with a temporal resolution of $1 \mathrm{~s}$ and has a spatial resolution of $30 \mathrm{~m}$ in the vertical and $200 \mathrm{~m}$ in the horizontal (McGill et al., 2002).

\section{Evidence of a central american dust barrier}

In this section we present observational evidence that suggests there is a persistent barrier to dust transport along the Central American coastline. Additionally, we present the representation of the barrier in GEOS-5 and utilize observations of a particular dust event from $\mathrm{TC}^{4}$ to evaluate GEOS-5 dust transport. 


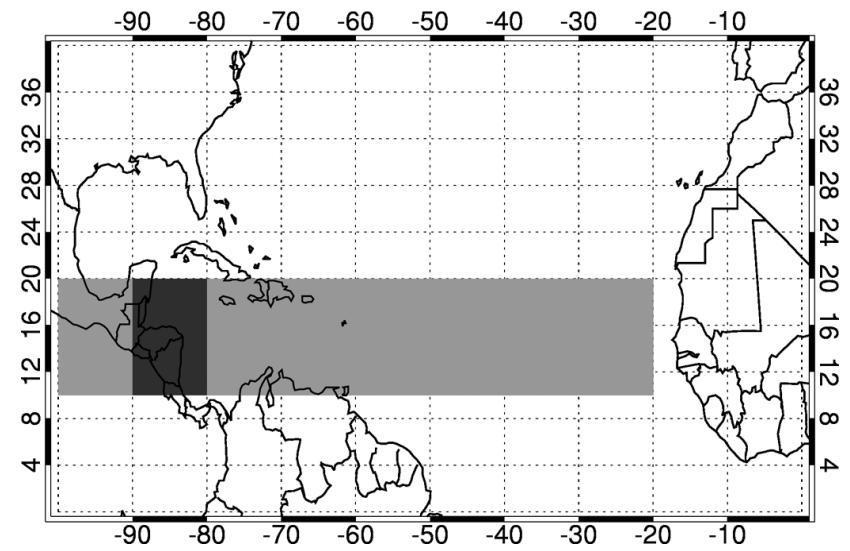

Fig. 1. Dust barrier-averaging regions (shaded).

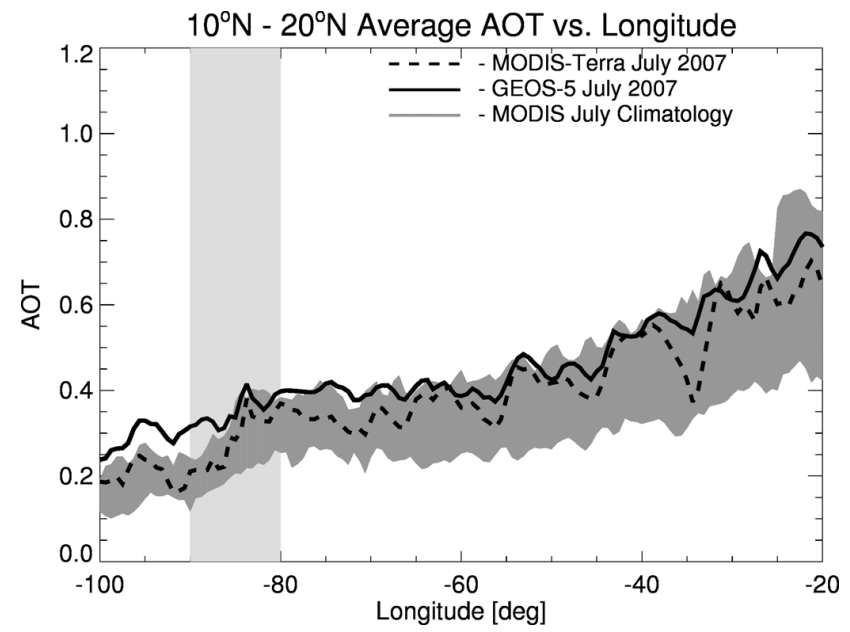

Fig. 2. MODIS-Terra/Aqua July climatological (2002-2010) AOT (shading), MODIS-Terra July 2007 AOT (dashed) and GEOS-5 sampled (solid) July 2007 AOT averaged from $10^{\circ}-20^{\circ} \mathrm{N}$.

\subsection{MODIS climatology}

Figure 2 shows the climatology of July MODIS-Aqua (20032010) and MODIS-Terra (2000-2010) land and ocean AOT averaged over the latitudes of peak Caribbean dust AOT $\left(10^{\circ} \mathrm{N}-20^{\circ} \mathrm{N}\right.$, see Fig. 1). There is a sharp drop in the observed AOT west of $80^{\circ} \mathrm{W}$. We refer to this strong gradient in AOT between about $80^{\circ}$ and $90^{\circ} \mathrm{W}$ as the Central American dust barrier, and we observe from the climatology of satellite observations that it is a persistent feature in the northern summer. In what follows we narrow our analysis to July 2007 to utilize observations made during the $\mathrm{TC}^{4}$ field campaign. Figure 2 also shows the MODIS-Terra AOT specifically for July 2007. There is evidence of the Central American dust barrier during this period, as the mean MODIS-Terra AOT drops from 0.375 at $80^{\circ} \mathrm{W}$ down to 0.2 at $90^{\circ} \mathrm{W}$.

To investigate the cause of the Central American dust barrier we performed a baseline GEOS-5 replay simulation us- ing the MERRA analyses. We simulate all aerosol types with radiative feedback to represent the effect of aerosol absorption and scattering (direct effect) on the atmosphere. After 75 days of model spin-up, we conduct our simulation from 15 June 2010 through 31 August 2010.

Figure 2 also shows the July 2007 AOT from the GEOS-5 model averaged over the same region. For this comparison we sample our modeled aerosol distributions at the times and locations of the MODIS observations, which has been shown to reduce biases between the MODIS and model AOT because of clouds (Colarco et al., 2010). Over the Caribbean (west of $60^{\circ} \mathrm{W}$ ), the model AOT is comparable to MODISTerra. Near the Central American coastline, the model shows evidence of a barrier to dust transport, although not as strong as observed, decreasing from 0.4 at $80^{\circ} \mathrm{W}$ to 0.3 at $90^{\circ} \mathrm{W}$ (Fig. 2).

For a spatial illustration of the Central American dust barrier, Fig. 3 shows July 2007 monthly means of total AOT from MODIS-Aqua and our simulation (sampled at MODISAqua observations points as described above). Off the west coast of North Africa, the model has the peak AOT in the same location as the sensor, but at a greater magnitude. Moving west across the tropical North Atlantic, the model matches the observed dust plume location and width, and the magnitude of AOT becomes more comparable with observations. Owing to improvements in the model physics and the MERRA analyses, GEOS-5 does better transporting dust from the Saharan source region to the Caribbean relative to previous versions of the model (Colarco et al., 2010; Nowottnick et al., 2010). However, consistent with Fig. 2, the model extends its dust plume somewhat into the eastern Pacific $\left(90^{\circ}-95^{\circ} \mathrm{W}\right)$, while MODIS-Aqua AOT values are constrained to the Caribbean. This feature is also seen in Fig. 2, where the model representation of the Central American dust barrier is not as pronounced as observed by MODIS-Terra. Despite not being as pronounced as observed by MODIS, the model shows evidence for a barrier to dust transport that corresponds with the Central American coastline.

\subsection{Central american dust barrier case study: 19 July 2007}

During the $\mathrm{TC}^{4}$ field campaign, a Saharan dust plume was observed over the Caribbean on 19 July with the CPL flying on the NASA ER-2 aircraft. Using CALIOP, we tracked this dust event from the Saharan source region (14 July) to the Caribbean (19 July) to evaluate our simulated vertical dust distributions during transport (Fig. 4). For an accurate comparison, we sampled GEOS-5 along the CALIPSO track at the model synoptic time nearest to the daytime CALIOP measurement. Shown in Fig. 5 are GEOS-5 comparisons to CALIOP $532 \mathrm{~nm}$ total attenuated backscatter and feature mask from 14 July to 19 July. On 14 July, CALIOP observes 
MODIS-Aqua and GEOS-5 AOT for July 2007
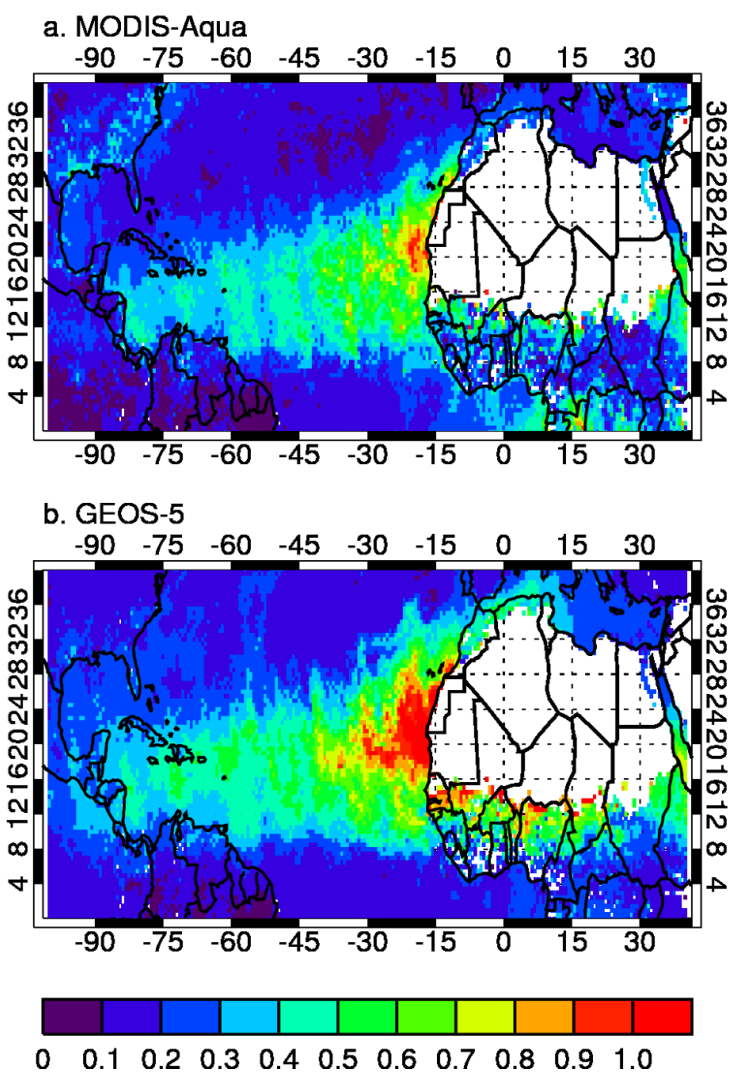

Fig. 3. MODIS-Aqua (a) and GEOS-5 sampled (b) July 2007 AOT.

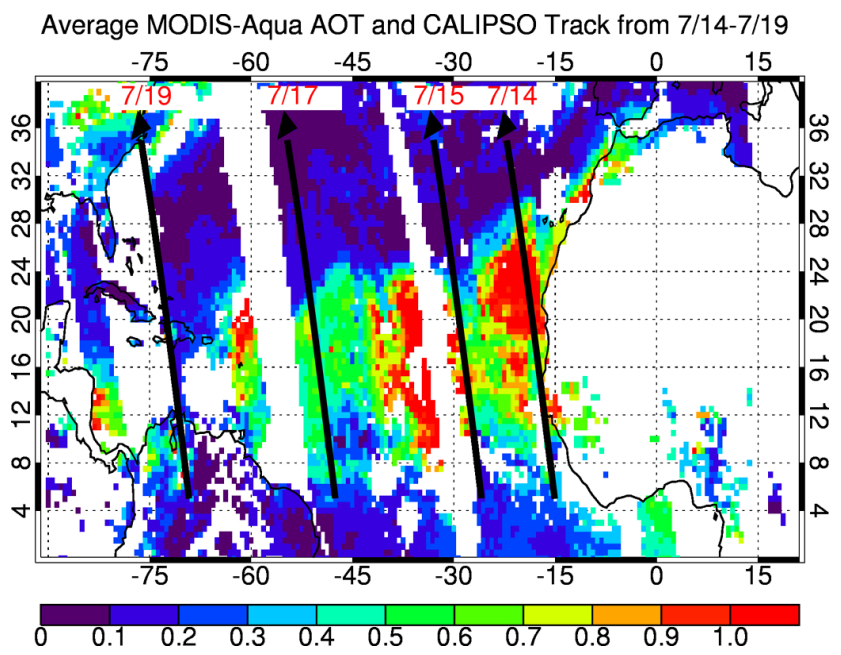

Fig. 4. Average MODIS-Aqua AOT and CALIPSO track from 1419 July.

a thick, elevated dust plume located from $2-5.5 \mathrm{~km}$ that extends from $10^{\circ}-26^{\circ} \mathrm{N}$. The model captures the latitude extent of the dust plume observed by CALIOP, but is lower in altitude ranging from $1-5.5 \mathrm{~km}$. A limitation of CALIOP is that its signal becomes attenuated towards the surface when it encounters thick aerosol plumes. On this day, the CALIOP signal might be partially attenuated at low altitudes, so the CALIOP data may suggest the lowest edge of the dust plume is at a higher altitude than it actually was. In the CALIOP layer identification product, low-level marine clouds are observed north of $15^{\circ} \mathrm{N}$ below $1 \mathrm{~km}$. While we only show extinction from aerosols, the influence of these clouds can be seen in the aerosol total extinction where the aerosols in this region have swelled in the marine boundary layer and are marked by high extinction values. Moving farther from the Saharan source region, the edge of a dust event is observed on 15 July. CALIOP observes an elevated, thick layer of dust that extends from $2-5 \mathrm{~km}$ between $11^{\circ}-24^{\circ} \mathrm{N}$, which is well represented in the model. Further downwind on $17 \mathrm{July}$, the model matches the observed horizontal extent and altitude of the observed dust plume. The simulated dust plume extends down to the surface into a region where CALIOP identifies a thin layer of maritime clouds, making it difficult to determine whether the lower extent of the simulated plume is correct. On 19 July, the model captures the narrow north-south width and low-altitude dust plume observed below $3 \mathrm{~km}$ by CALIOP, although clearly the observations are impacted by the presence of mid- and low-level clouds. In general, we see for this case that GEOS-5 is capturing similar dust plume features to the CALIOP observations during this time period.

Figure 6 shows the composite MODIS-Terra/Aqua and GEOS-5 $550 \mathrm{~nm}$ AOT at 18Z, with the ER-2 flight track overlaid on 7/19. On this day, the ER-2 aircraft originated from Costa Rica, heading southwest over the Pacific Ocean to $90^{\circ} \mathrm{W}$, then turned around and headed northeast back towards Costa Rica. The aircraft continued past Central America over the Caribbean Sea to $75^{\circ} \mathrm{W}$ and then headed southwest back to Costa Rica. During the flight, CPL provided an approximately east-west transect of total attenuated backscatter that extends from the Pacific Ocean into the Caribbean. Comparing the model to MODIS on this day, the model matches the observed AOT location and magnitude over the Caribbean. Over the Pacific Ocean MODIS is partially obscured by precipitating clouds. Also displayed in Fig. 6 are the observed daily precipitation $\left(\mathrm{mm} \mathrm{day}^{-1}\right)$ from the Global Precipitation Climatology Project (GPCP) (Huffman et al., 2009; Adler et al., 2003) and the simulated daily precipitation from GEOS-5 with the $700 \mathrm{mb}$ wind field at $18 \mathrm{Z}$ overlaid. GPCP provides precipitation data at $1^{\circ} \times 1^{\circ}$ resolution using rain gauges, microwave satellite observations from the Special Sensor Microwave Imager (SSM/I), and infrared satellites observations from many global geostationary satellites (Adler et al., 2003). The model shows a majority of the simulated AOT confined to the Caribbean and Central America and also simulates precipitation over the Pacific Ocean. Additionally, the simulated $700 \mathrm{mb}$ wind field suggests that the direction of dust transport might shift northward over the Central American coastline. 
$7 / 14$
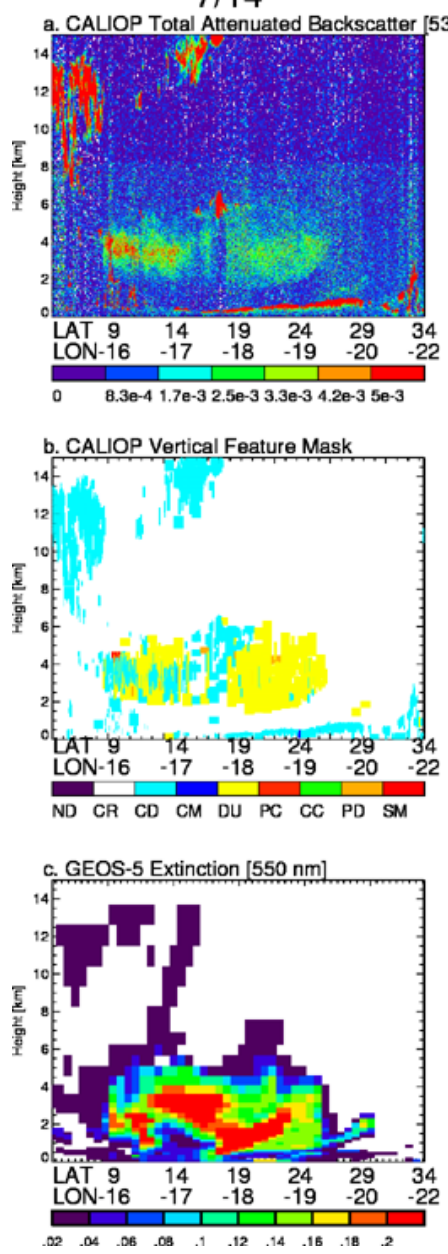

$7 / 15$

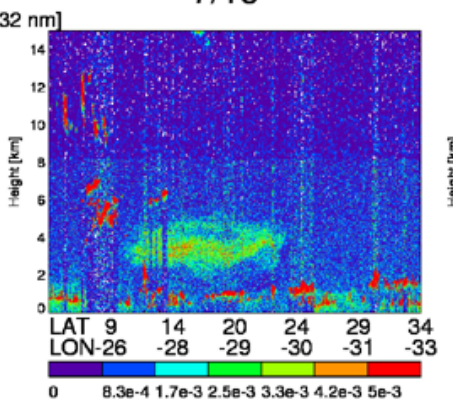

0 8.3e-4 1.7e-3 2.5e-3 3.3e-34.2e-3 5e-3

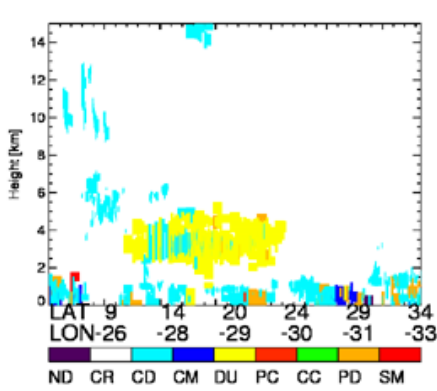

$7 / 17$
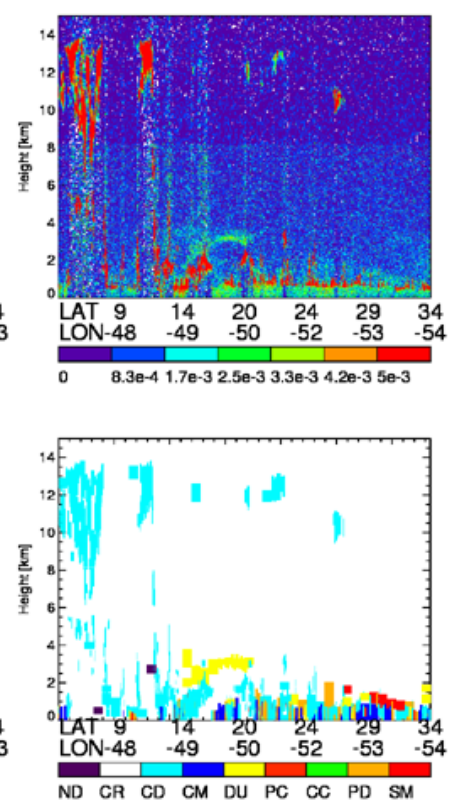

$7 / 19$
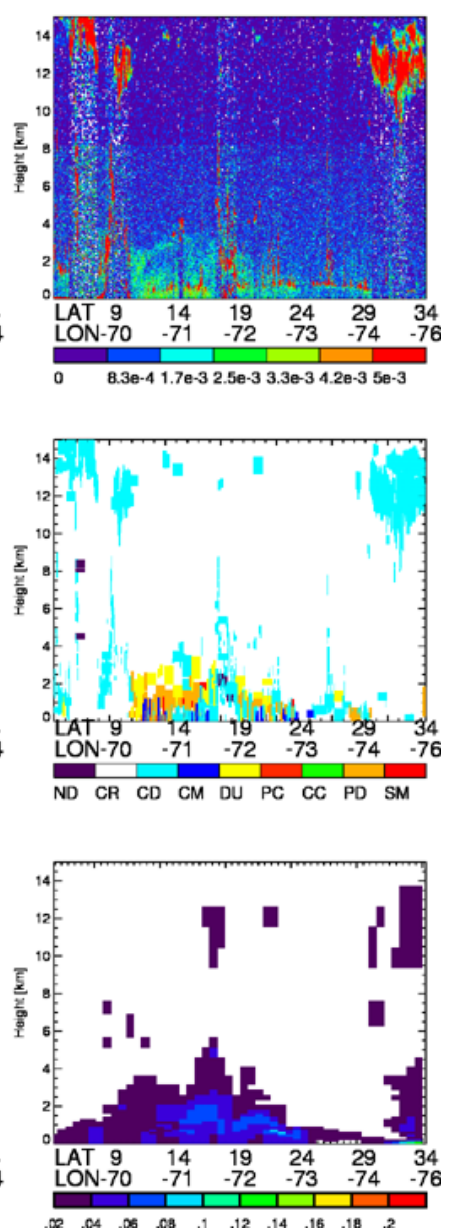

Fig. 5. CALIOP total attenuated backscatter $\left(\mathrm{km}^{-1} \mathrm{sr}^{-1}\right)$ (a), CALIOP vertical feature mask (b), and GEOS-5 extinction (km $\left.{ }^{-1}\right)(\mathbf{c})$ for a dust event tracked from Africa (14 July) to the Caribbean (19 July).

The dust barrier is more clearly seen in the CPL profile of the $532 \mathrm{~nm}$ total attenuated backscatter and column AOT when compared to GEOS-5 profiles of extinction and AOT at $550 \mathrm{~nm}$ that have been sampled along the ER-2 track at the nearest model synoptic time on 7/19 (Fig. 6). Although the CPL signal is frequently attenuated by clouds over the Pacific and only occasionally over the Caribbean, both CPL and GEOS-5 provide an illustration of the Central American dust barrier along the eastern coastline of Costa Rica $\left(9^{\circ} \mathrm{N}\right.$, $84^{\circ} \mathrm{W}$, marked by a mountain). To avoid cloud contributions to the AOT, we compare the column AOT from $5 \mathrm{~km}$ to the surface for CPL and GEOS-5 (Fig. 6). CPL observes high AOT values over the Caribbean, and a sharp decrease in AOT that corresponds with the Central American coastline. A similar feature is seen in the simulated AOT, but at a lower magnitude. Despite this, it is clear that GEOS-5 provides a representation of the Central American dust barrier on this day and suggests two processes that may contribute its cause: removal by precipitation in the tropical environment and a directional shift in the wind field near the Central American coastline.

\section{Controls on saharan dust during transport}

To understand the cause of the Central American dust barrier, we must understand the roles of the controls on dust distributions during transport. Once emitted from the source region, dust is further lifted into the atmosphere through dry convection and turbulent eddies to form an elevated layer, often penetrating into the so-called Saharan Air Layer (SAL) of hot, dry air (Karyampudi, 1999). During summer months, a surface north-south temperature gradient forms between the hot Sahara and the relatively cooler Sahel (Cook et al., 1999). Through thermal wind balance, this leads to the summertime African Easterly Jet (AEJ). During AEJ formation, the SAL 


\section{Dust Over the Caribbean during $\mathrm{TC}^{4}$ on $7 / 19 / 2007$}

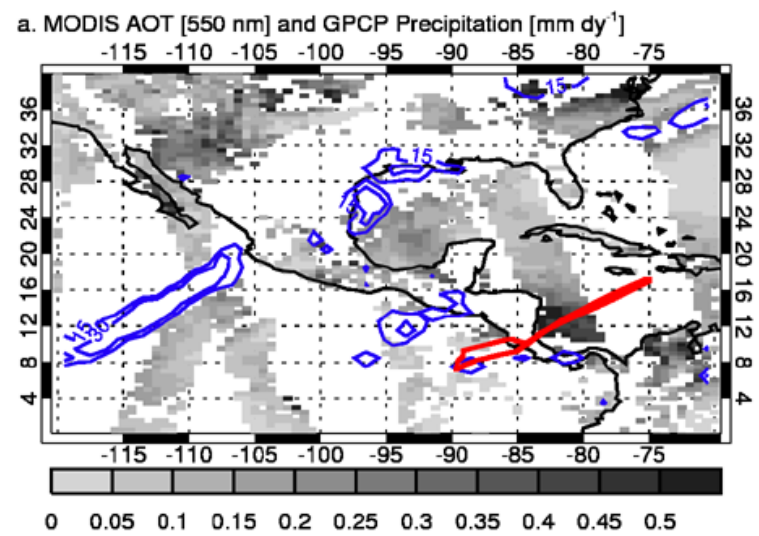

b. GEOS-5 AOT [550 nm], Precipitation [mm dy ${ }^{-1}$, and $700 \mathrm{mb}$ Winds [m s $\mathrm{m}^{-1}$,

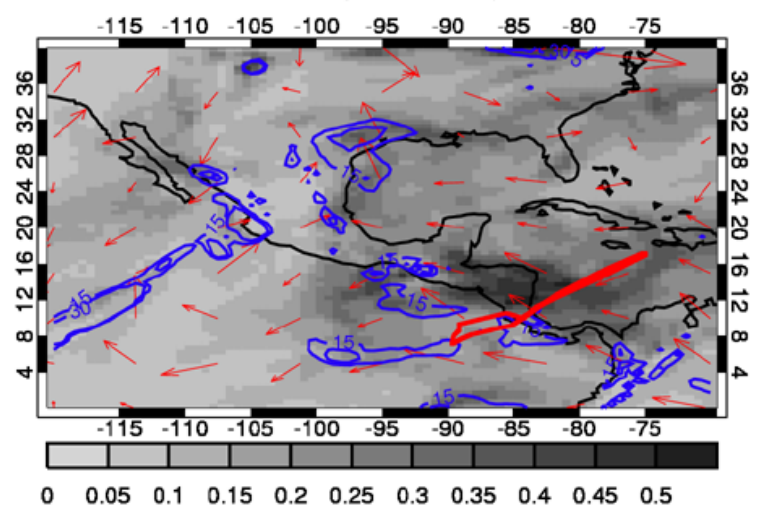

c. CPL Total Attenuated Backscatter [532 nm]

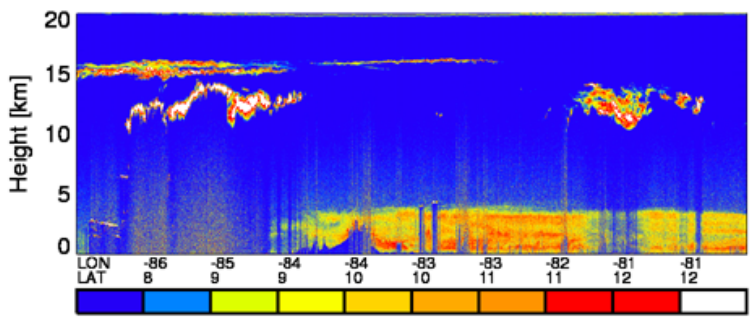

0 1e-6 1.5e-6 2e-6 2.5e-6 3e-6 3.5e-6 4e-6 4.5e-6 5e-6

d. GEOS-5 Total Extinction [550 nm]

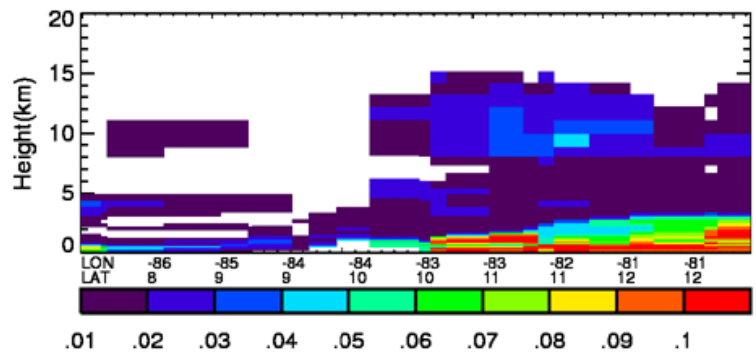

e. CPL [532 nm] and GEOS-5 [550 nm] Column AOT

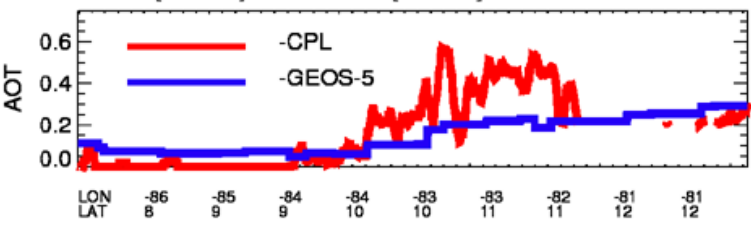

Fig. 6. MODIS Aqua AOT, GPCP precipitation (blue contour), and ER-2 flight track (red) (a), GEOS-5 AOT, precipitation (blue contour), $700 \mathrm{mb}$ wind field (red arrows), and ER-2 flight track (red) (b), CPL total attenuated backscatter $\left(\mathrm{km}^{-1} \mathrm{sr}^{-1}\right)(\mathbf{c}), \mathrm{GEOS}^{-5}$ extinction (km $\left.{ }^{-1}\right)$ (d), CPL AOT below $5 \mathrm{~km}$ (red) and GEOS-5 AOT below $5 \mathrm{~km}$ (blue) (e) on 19 July 2007.

converges on the north side of the AEJ axis and is then transported along the north side of the AEJ, delivering dust to the Caribbean. During the journey from the Sahara to the Caribbean, dust distributions are controlled by both dynamical and loss processes. Atmospheric dynamics controls the direction and magnitude of the transported dust mass flux or flow, while loss processes control the overall dust burden. Therefore, as suggested by Fig. 6, we suspect that the Central American dust barrier is caused by increases in wet removal, a change in transport direction resulting from a shift in the prevailing atmospheric dynamics, or some combination of both.

Ideally, we would have airborne measurements while tracking several dust plumes to help understand cause of the Central American dust barrier. Unfortunately, measurements of this sort are extremely limited. However, from our comparisons to observations of mean dust plume position and vertical distributions near and downwind of the Saharan source region, GEOS-5 provides a reasonable representation of dust distributions during the $\mathrm{TC}^{4}$ timeframe, while simulating the aforementioned processes that are not easily measured. The accuracy of our simulated wet removal processes are directly linked to our ability to accurately simulate the timing and intensity of precipitation events. Figure 7 shows the July 2007 mean precipitation from GPCP $\left(\mathrm{mm} \mathrm{day}^{-1}\right)$ and GEOS-5. The precipitation patterns in GEOS-5 are generally consistent with GPCP, matching peak values located over Central and South America. However, GEOS-5 produces a broad area of convective precipitation over the Caribbean that is not seen in the GPCP data. Over the Caribbean, the average GEOS-5 precipitation rate is $5 \mathrm{~mm}$ day $^{-1}$ while the average GPCP precipitation rate is $1.5 \mathrm{~mm} \mathrm{day}^{-1}$. This presents an interesting feature of the model. Figure 2 suggests that our removal rates are not aggressive enough in removing dust, particularly in the region of the Central American dust barrier. However, on average, our precipitation rate is greater by a factor of three (Fig. 7). This quandary suggests that the relationship between precipitation and wet removal is not strong enough in our model. We could, alternatively, simply rescale our dust emissions 


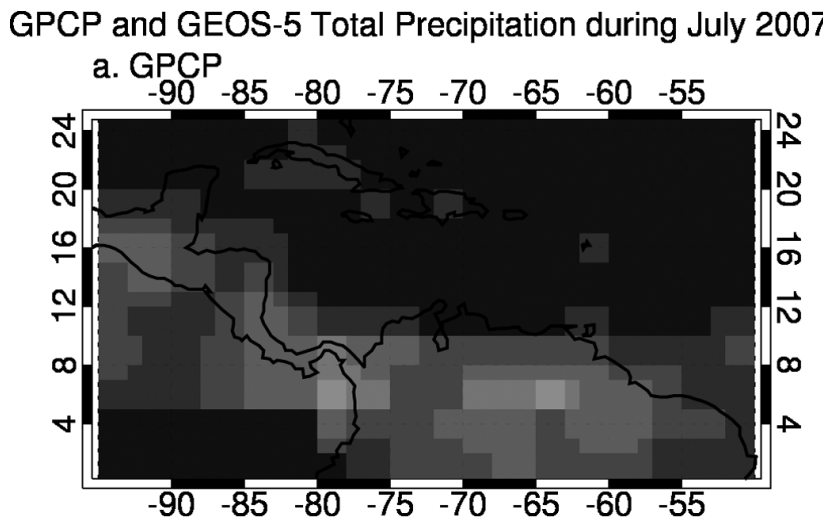

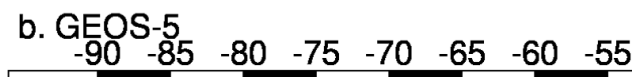

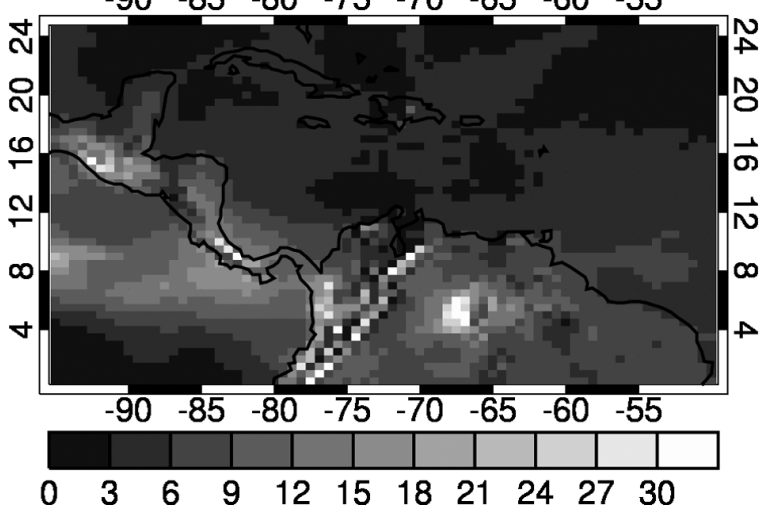

Fig. 7. July 2007 monthly mean GPCP (a) and GEOS-5 (b) total precipitation $\left(\mathrm{mm} \mathrm{day}^{-1}\right)$.

lower, which would remove most of the bias seen in Fig. 2, but this would not produce the abrupt dust barrier evident in the data at approximately $90^{\circ} \mathrm{W}$.

In addition to possible errors in our representation of loss processes, our simulated dust distributions are sensitive to atmospheric dynamics. By using a replay simulation, we are providing the model with assimilated winds, so that it will be forced with actual dynamics at each synoptic time. Our estimation of dust transport is therefore sensitive to our ability to reproduce the actual dynamical state and will be limited by errors in the representations of advection, planetary boundary layer mixing, and convective mixing. In addition to sensitivities to the internal dynamical processes, simulated dust distributions will also be sensitive to the accuracy of observations used in the analysis. Despite these potential sources of error, however, our July 2007 simulated dust loading over the Caribbean is comparable to observations by MODIS in Sect. 3. Therefore, we use our dust distributions from GEOS5 to understand the relative roles of the processes that contribute to the Central American dust barrier.

To investigate the controls on the Central American dust barrier, we employ the vertically integrated mass divergence form of the continuity equation for mean values from July 2007:

$\frac{\partial q}{\partial t}=(\mathrm{P}-\mathrm{L})-\nabla \cdot \vec{Q}$

where $q$ is the column dust loading defined:

$q=\sum_{z=0}^{z=\text { top }} \gamma \cdot \rho_{\text {air }} \cdot d z$

and $\vec{Q}$ is the vertically integrated dust mass flux:

$$
\vec{Q}=\begin{aligned}
& \sum_{z=0}^{z=\text { top }} \gamma \cdot \rho_{\mathrm{air}} \cdot u \cdot d z \cdot \hat{i} \\
& +\sum_{z=0}^{z=\text { top }} \gamma \cdot \rho_{\mathrm{air}} \cdot v \cdot d z \cdot \hat{j}
\end{aligned}
$$

Here, $\gamma$ is the dust mass mixing ratio $\left(\mathrm{kg} \mathrm{kg}^{-1}\right), \rho_{\text {air }}$ is the atmospheric air density $\left(\mathrm{kg} \mathrm{m}^{-3}\right), \mathrm{u}$ and $\mathrm{v}$ are the east-west and north-south components of the wind field $\left(\mathrm{m} \mathrm{s}^{-1}\right)$, and $d z$ is the thickness $(\mathrm{m})$ of each model layer in the vertical column.

After integrating in the vertical, Eq. (1) has three terms: the storage term $\left(\frac{\partial q}{\partial t}\right)$, the production-loss $(\mathrm{P}-\mathrm{L})$ term, and the divergence, or transport, term $(\nabla \cdot \vec{Q})$. The storage term represents the net local change in the dust column loading, the P-L term is defined as the sum of the column emission fluxes minus fluxes due to dry and wet removal, and the transport term represents any dust column convergence and divergence resulting from transport. All terms in Eq. (1) are in flux form and have the units $\left(\mathrm{kg} \mathrm{m}^{-2} \mathrm{~s}^{-1}\right)$. Equation (1) can be interpreted as any accumulation of dust mass within an atmospheric column results from the sum of the net production minus loss and dust import/export via transport.

To relate the contribution of transport to Eq. (1), we begin with our vertically integrated dust mass flux $\vec{Q}\left(\mathrm{~kg} \mathrm{~m}^{-1} \mathrm{~s}^{-1}\right)$ (Eq. 3). Because dust is typically located at low altitudes, $\vec{Q}$ will be weighted toward the mass concentration and the near-surface wind direction and magnitude.

Consider the Helmholtz decomposition (Brown, 1991):

$\vec{Q}=\vec{Q}_{\operatorname{rot}}+\vec{Q}_{\operatorname{div}}$

where $\vec{Q}$ rot and $\vec{Q}$ div are the rotational and divergent components of the vertically integrated mass flux vector $\vec{Q}$, with $\nabla \cdot \vec{Q}$ rot $=0$ and $\nabla \times \vec{Q}$ div $=0$ by definition. The corresponding mass flux streamfunction $\psi$ and velocity potential $\chi$ can be obtained by solving Poisson's equations (Brown, 1991):

$$
\begin{aligned}
& \nabla^{2} \Psi=\nabla \cdot \vec{Q}_{\text {div }} \\
& \nabla^{2} \chi=\hat{k} \cdot \nabla \times \vec{Q}_{\text {rot }}
\end{aligned}
$$




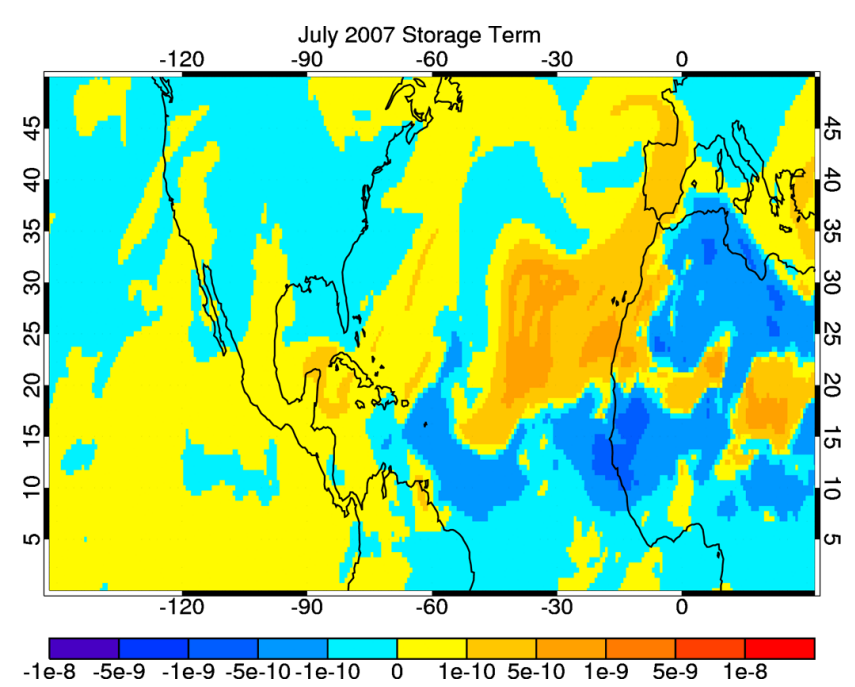

Fig. 8. July 2007 storage term $\left(\mathrm{kg} \mathrm{m}^{-2} \mathrm{~s}^{-1}\right)$ as described in Sect. 4.1.1.

from which we obtain the divergent and rotational components of $\vec{Q}$ :

$$
\begin{aligned}
\vec{Q}_{\text {rot }} & =-\frac{\partial \Psi}{\partial y} \hat{i}+\frac{\partial \Psi}{\partial x} \hat{j} \\
\vec{Q}_{\text {div }} & =\frac{\partial \chi}{\partial x} \hat{i}+\frac{\partial \chi}{\partial y} \hat{j}
\end{aligned}
$$

The rotational component depicts the recirculation of dust in the atmosphere, while the divergent component of the vertically integrated mass flux is associated with the P-L process $(\nabla \cdot \vec{Q} \operatorname{div}=\nabla \cdot \vec{Q})($ Eq. 1$)$

\subsection{Dust mass budget}

In this section, we analyze the July 2007 monthly mean storage, P-L, and transport terms. We analyze each term separately to understand their respective influence on our simulated dust distributions over the Caribbean. Our calculation of Eq. (1) uses instantaneous model output at every $3 \mathrm{~h}$ to determine the monthly mean dust mass fluxes; thus, the fields examined include both the mean flow and the contribution from transient eddies.

\subsubsection{Storage term}

At each grid cell, the storage term represents the mean local change in the column dust loading $q\left(\mathrm{~kg} \mathrm{~m}^{-2}\right)$ (Eq. 2). During July 2007, the largest variations in the dust column loading occur away from regions of semi-persistent dust flow (Fig. 8). This can be seen north of $20^{\circ} \mathrm{N}$ off the west coast of North Africa during July 2007, where removal rates are small (Fig. 8). Eventually, this dust will be removed from the atmosphere via loss processes or transport. Over the Caribbean,

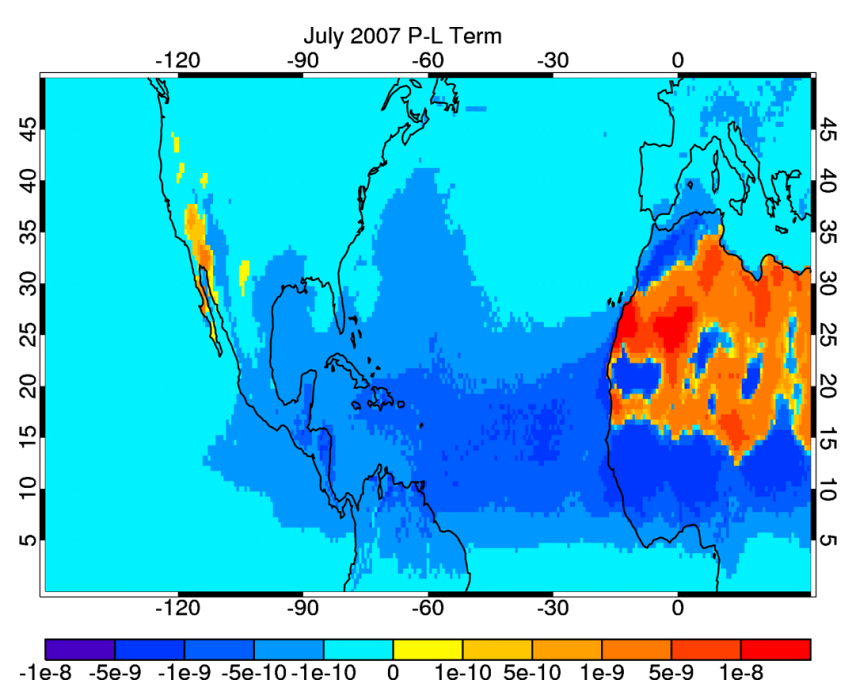

Fig. 9. July 2007 production minus loss (P-L) term $\left(\mathrm{kg} \mathrm{m}^{-2} \mathrm{~s}^{-1}\right)$ as described in Sect. 4.1.2.

the storage term is significantly less than the P-L and transport terms, indicating that the other terms are in near-balance over this region. Over longer time periods, we expect the storage term to approach zero, as deviations in the mean dust flow will become less significant and averaged out. In this case, the P-L term will balance the transport term.

\subsubsection{P-L term}

The mean P-L term for July 2007 shows positive values over the global source region and negative values downwind, corresponding to regions where emissions and losses prevail, respectively (Fig. 9). Once dust is emitted from the source region, the total atmospheric burden is controlled by losses through dry and wet removal processes. In the Atlantic, losses peak immediately downstream of the source region, although a broad area of high dust losses carries into the Caribbean.

Figure 10 shows the relative contributions from our modeled dust loss processes during transport from the source region. Dry removal (dry deposition + sedimentation) is the dominant removal process near the Saharan source region, as the largest, most massive dust particles fall quickly from the atmosphere. Dry removal becomes less significant further downwind as the largest particles are removed. Wet removal becomes the dominant loss process, first via large-scale precipitation immediately west of the source region and then through convective precipitation in the western Caribbean and near Central America. This region where convective removal dominates coincides with the location of the Central American dust barrier. 


\section{July 2007 Loss Process Contributions}
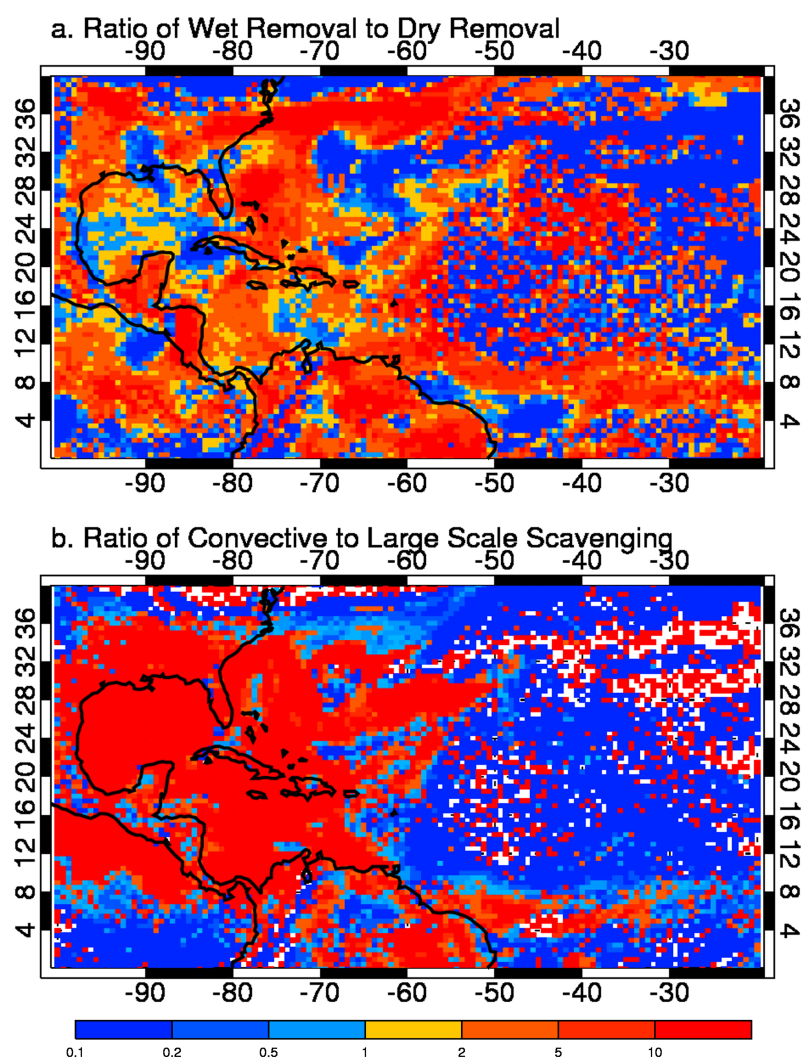

Fig. 10. (a) July 2007 ratio of wet removal to dry removal and (b) ratio of convective to large scale scavenging.

\subsubsection{Transport term}

Shown in Fig. 11 are the July 2007 mean streamfunction and velocity potential contours with the rotational and divergent dust flow vectors overlaid. We recall that the rotational component of the dust flow is proportional to the curl of the streamfunction; therefore, rotational flow will be strongest where streamlines are closest. By definition, the rotational flow will be cyclonic surrounding relative minima of the streamfunction, and anti-cyclonic surrounding the relative maxima. We see strong rotational dust flow leaving the Sahara as part of the SAL and riding on the northern side $\left(15^{\circ}-\right.$ $25^{\circ} \mathrm{N}$ ) of the AEJ across the Atlantic Ocean. In this region, the rotational component of the dust flow is strong for two reasons: (1) dust concentrations are high within the SAL and (2) strong, non-divergent easterlies within the AEJ persist. The effect is a narrow band $\left(15^{\circ}-25^{\circ} \mathrm{N}\right)$ of strong rotational flow that transports dust from the Sahara to the Caribbean. Upon reaching the Caribbean, the rotational flow weakens because: (1) dust loss processes have reduced the overall dust load during transport and (2) easterly wind speeds are re-

\section{Components of Dust Flow for July 2007}
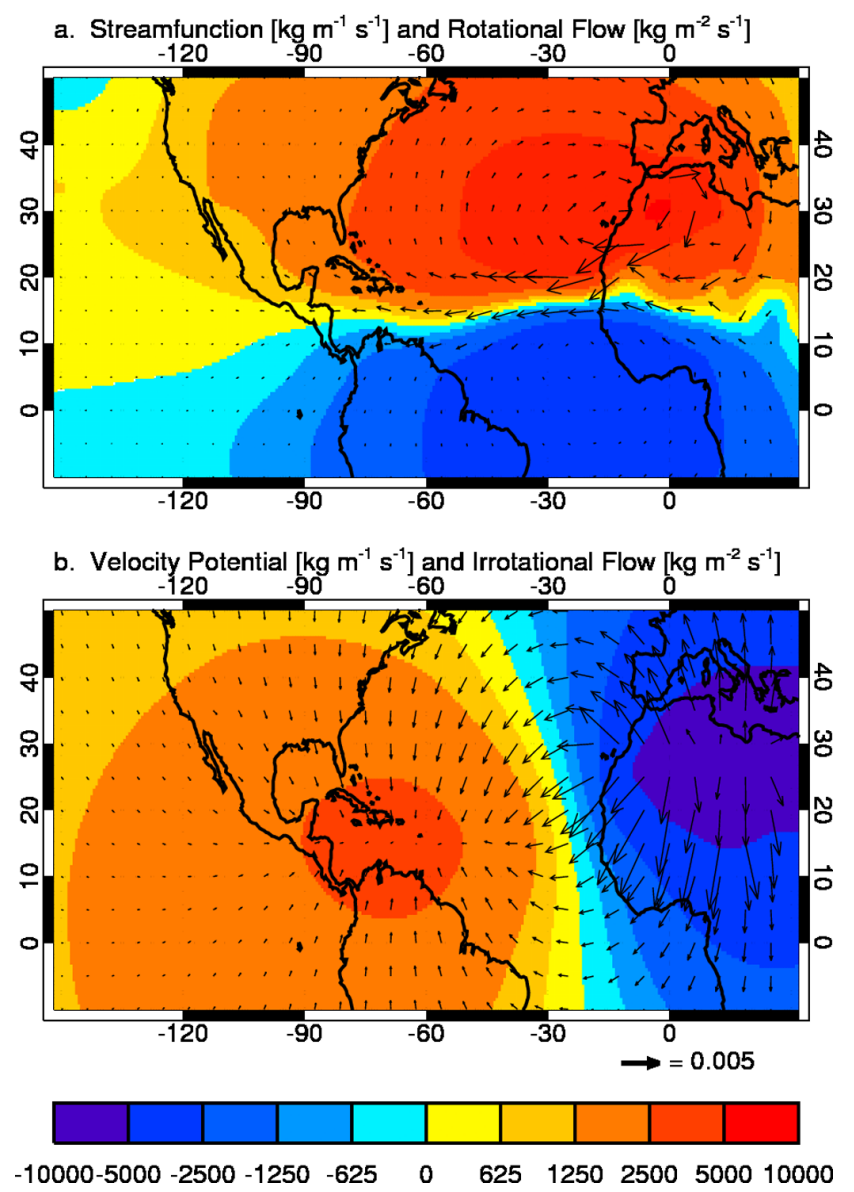

Fig. 11. July 2007 mean streamfunction (a) and velocity potential (b). Rotational (top) and irrotational (bottom) flows are indicated by vectors.

duced. Additionally, the flow direction shifts from primarily westward to north-westward over the Caribbean as it is now influenced by the Azores subtropical high-pressure system that exists over the Atlantic Ocean. The rotational dust flow eventually turns eastward and returns dust back to the Saharan source region. Thus, when following a constant streamline, the rotational component of Saharan dust flow is an anticyclonic recirculation, where dust leaves the source region as part of the AEJ and returns with the westerlies as part of the Azores High. A similar-but weaker-cyclonic feature is seen south of $15^{\circ} \mathrm{N}$, transporting dust to South America.

The divergent component of the flow is proportional to the gradient of the velocity potential. Therefore, regions of divergence correspond to relative minima of the velocity potential correspond, while regions of convergence correspond to relative maxima. In Fig. 11, we see a dipole in the divergent flow field between the Saharan source region and the Caribbean. Over the source region strong divergent flow persists, as a divergent component to the dust flow is required 


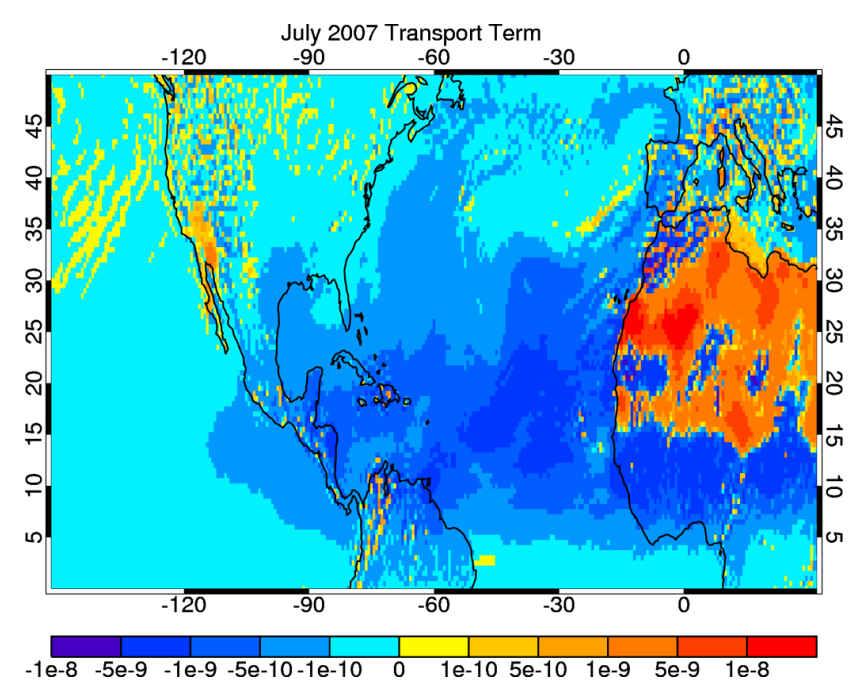

Fig. 12. July 2007 production minus loss (P-L) term $\left(\mathrm{kg} \mathrm{m}^{-2} \mathrm{~s}^{-1}\right)$ as described in Sect. 4.1.3.

for dust to leave the source region. During transport, the divergent flow is significantly reduced and there is a broad, region of convergence over the Caribbean where loss processes prevail. The significant reduction in the divergent flow can be the result of a weakening of the wind field or a reduction in the dust burden caused by the various loss processes during transport. As previously mentioned, the divergence of the divergent flow $\left(\nabla \cdot \vec{Q}_{\text {div }}\right)$ is the transport term in Eq. (1). In Fig. 12, as expected, the July 2007 transport term is positive (divergent) over the source regions, as dust is transported outward from the sources. Downwind of the Saharan source region, the transport term is negative (convergent), which corresponds with the convergent flow field in Fig. 11. One striking feature of the divergence field is that it aligns with the P-L term in regions where production and loss occur. Because these regions have a semi-persistent flow of dust for this month and the storage term is small, there is a near-balance between the transport and P-L terms. Thus, over these regions, regions of dust emission $(\mathrm{P}-\mathrm{L}>0$ ) correspond with divergent outflow (positive transport term) and regions of dust loss $(\mathrm{P}-\mathrm{L}<0)$ correspond with convergent inflow (negative transport term). We expect that convergent flow increases dust loss rates in two ways. First, the convergent flow will accumulate dust within the atmospheric column. This accumulation will increase the potential for removal in regions where the storage term is small. Second, we find vertical motion over convergent regions (not shown), which is associated with convection. This second process is more relevant for wet removal as we expect greater wet deposition and scavenging rates in the presence of precipitation and clouds.

Despite the link between P-L and divergent flow, it is clear that rotational flow has a greater magnitude and is in a different direction (predominantly westward) than the divergent flow (predominantly eastward). However, this alone does not lend much insight into any influences that transport might have on the Central American dust barrier. In addition to the effects of loss processes, the dust barrier could be influenced by a slight change to the flow field over the Caribbean or a combination of the rotational and divergent components. To better understand this, we further break the rotational and divergent components into their east-west and north-south components. Figure 13 shows the east-west and north-south total, rotational, and divergent flow components. Over the Caribbean, the rotational component of the east-west flow is strongly westward while the divergent component is weakly eastward. Despite cancellation between the two components near the coast of Costa Rica, the net east-west flow is westward and acts to transport dust across Central America. The north-south flow for the rotational component shifts from southward to northward near $12.5^{\circ} \mathrm{N}$ over the Caribbean, while the divergent flow shifts from northward to southward flow at $17.5^{\circ} \mathrm{N}$. However, the net north-south flow is northward over the entire Caribbean. Thus, there is a northward turning of the dust flow as it enters the Caribbean, which when combined with the net westward flow causes a northwestern migration of the overall dust flow and serves as a possible explanation of the Central American dust barrier.

\subsection{Loss processes vs. transport}

We investigate the dust mass budget in the latitude band of peak dust AOT $\left(10^{\circ}-20^{\circ} \mathrm{N}\right)$ to understand the relative roles of dust loss processes and transport in the Central American dust barrier. Figure 14 shows the mass of dust removed from loss processes, from transport out of the northern $\left(20^{\circ} \mathrm{N}\right)$ and southern $\left(10^{\circ} \mathrm{N}\right)$ sides of the latitude band, and the change in the east-west mass flux (flux in minus flux out) as a function of longitude. To obtain the amount of dust lost via removal, we integrate the P-L rates spatially and temporally and sum over the latitude band at each longitude (black curves in Fig. 14). To quantify the net north-south dust mass flux out of the band, we subtract the net spatially and temporally integrated north-south dust flux at $20^{\circ} \mathrm{N}$ from that at $10^{\circ} \mathrm{N}$ at each longitude (Fig. 14). To obtain the change in the eastwest mass flux, we first integrate the net east-west component of the dust flow spatially and temporally at each grid box. The change in the east-west mass flux is then determined by differencing the east-west flow in the westward direction and then summing along all latitudes (Fig. 14). Negative mass values in Fig. 14 correspond with net loss via removal processes or transport out of the latitude band, or a reduction in the westward mass flux. It should be noted that the sum of the net north-south mass flux and the change in the westward mass flux is the divergence term in Eq. (1). This sum is approximately equal to the mass of dust removed by loss processes, with any residual related to the storage term.

Over the Caribbean, removal from loss processes and northward transport were shown to serve as possible causes 


\section{East-West and North-West Components of Dust Flow $\left[\mathrm{kg} \mathrm{m}^{-2} \mathrm{~s}^{-1}\right]$ during July 2007}

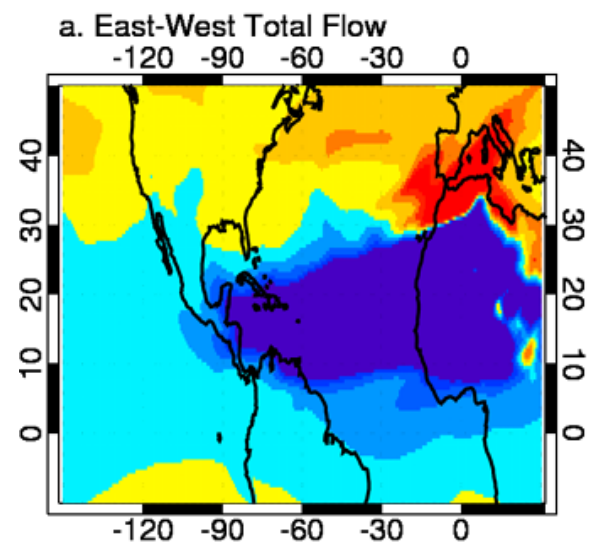

b. East-West Rotational Flow

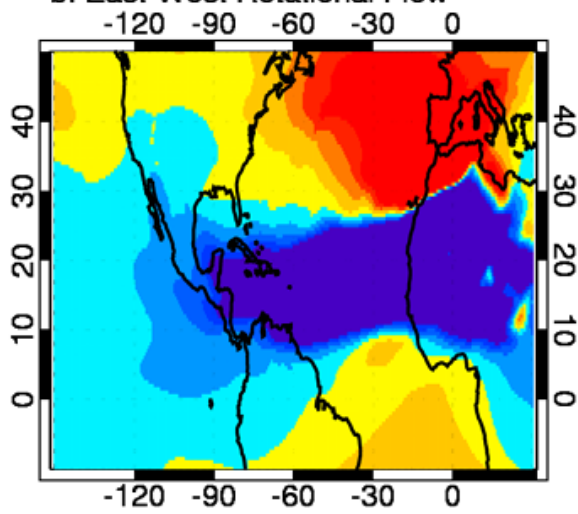

c. East-West Irrotational Flow

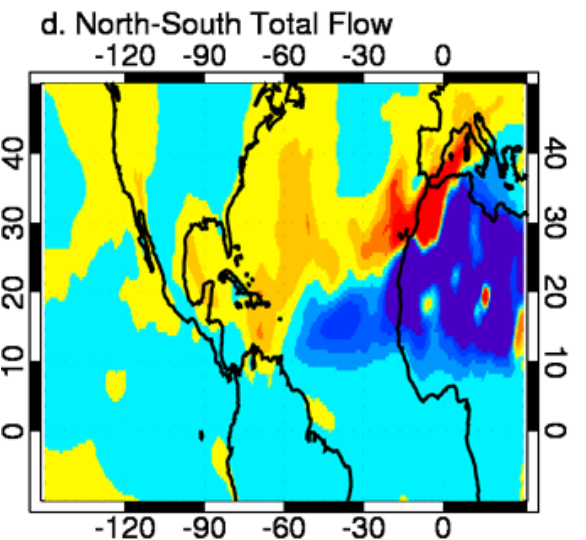

e. North-South Rotational Flow
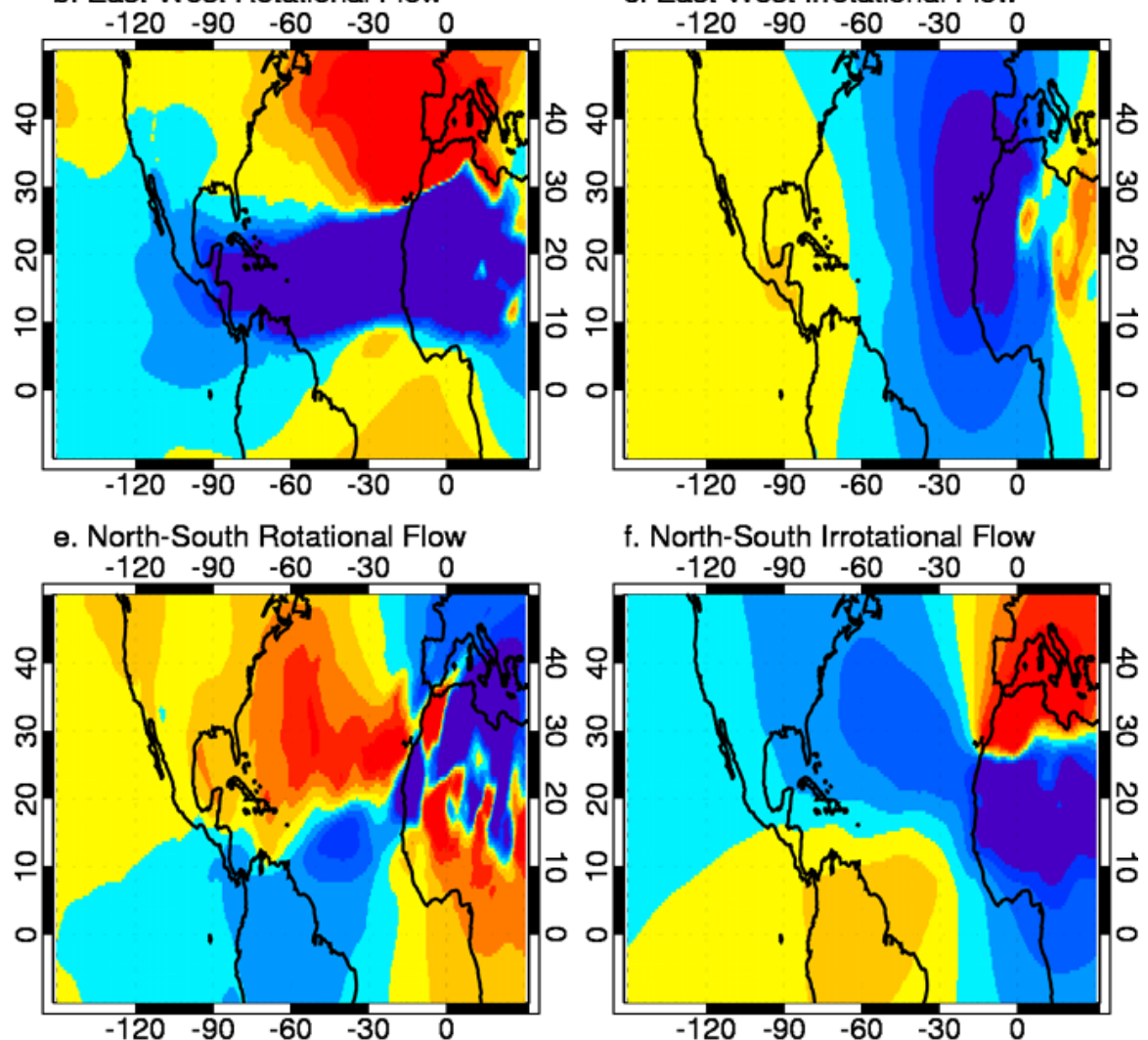

f. North-South Irrotational Flow
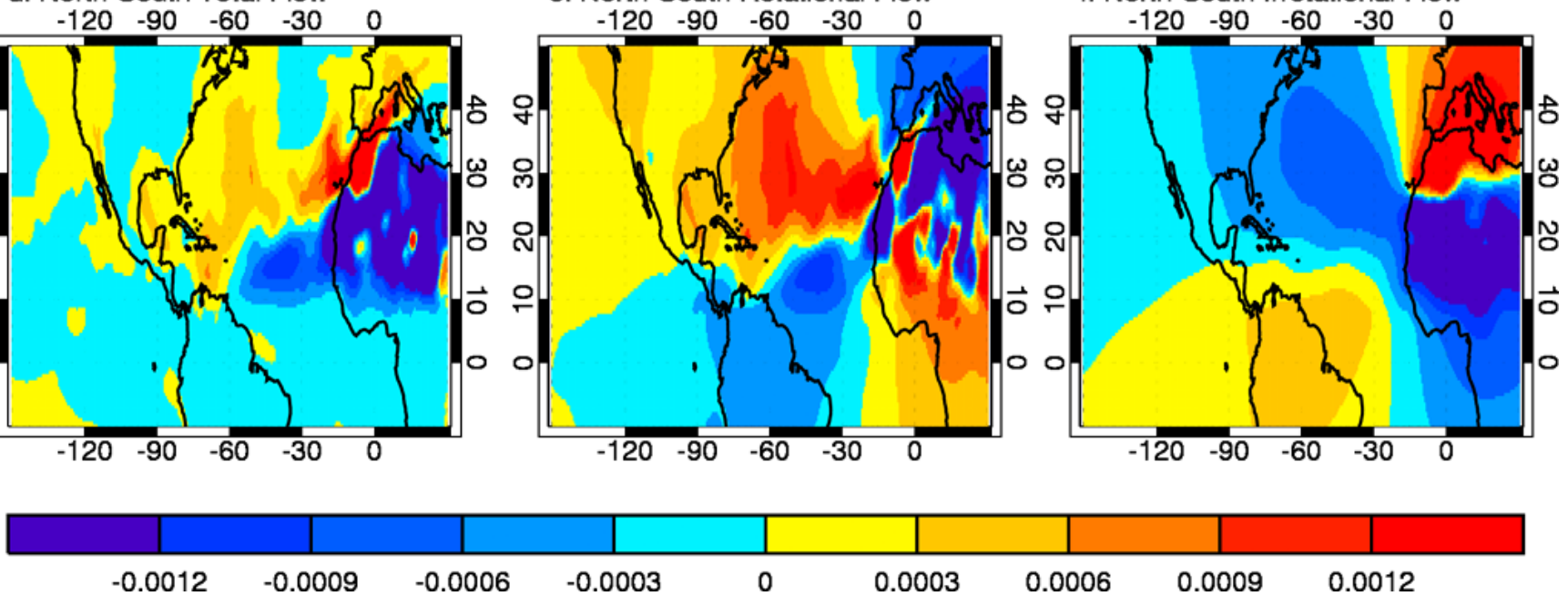

Fig. 13. East-west (top) and north-south components (bottom) of the total (left), rotational (center), and divergent (right) flow.

Table 1. Net northward mass transport and mass loss from removal and relative contribution, westward mass transport at entrance and exit of barrier region, and mass, total AOT, and coarse mode barrier efficiencies for all simulations and MODIS-Terra.

\begin{tabular}{|c|c|c|c|c|c|c|}
\hline Experiment/Satellite & $\begin{array}{r}\text { Net Northward } \\
\text { Mass Transport }(\mathrm{Tg}) \text { and } \\
\text { Barrier Contribution }(\%)\end{array}$ & $\begin{array}{r}\text { Net Mass Loss from } \\
\text { Removal }(\mathrm{Tg}) \text { and } \\
\text { Barrier Contribution }(\%)\end{array}$ & $\begin{array}{r}80^{\circ} \mathrm{W}, 90^{\circ} \mathrm{W} \text {, and } \\
\text { Net Change in Westward } \\
\text { Transport }(\mathrm{Tg})\end{array}$ & Mass & $\begin{array}{r}\text { Barrier } \\
\text { Efficiency } \\
\text { Total AOT }\end{array}$ & $\begin{array}{r}\text { Coarse } \\
\text { Mode AOT }\end{array}$ \\
\hline 1. Baseline & $-1.46 \mid 47 \%$ & $-1.67 \mid 53 \%$ & $-7.58|-4.21| 3.37$ & 0.36 & 0.21 & 0.17 \\
\hline 2. Doubled Convective Scavenging & $-1.24 \mid 39 \%$ & $-1.90 \mid 61 \%$ & $-6.51|-3.40| 3.11$ & 0.48 & 0.25 & 0.21 \\
\hline 3. Wet Removal Treated As Other Aerosols & $-1.02 \mid 34 \%$ & $-1.97 \mid 66 \%$ & $-5.42|-2.60| 2.82$ & 0.52 & 0.28 & 0.22 \\
\hline 4. No Large Scale Scavenging & $-1.85 \mid 59 \%$ & $-0.95 \mid 41 \%$ & $-9.76|-6.88| 3.87$ & 0.33 & 0.19 & 0.16 \\
\hline 5. No Wet Removal & $-3.35 \mid 78 \%$ & $-1.28 \mid 22 \%$ & $-18.73|-13.96| 4.77$ & 0.25 & 0.17 & 0.13 \\
\hline 6. MODIS-Terra & - & - & - & - & 0.37 & 0.30 \\
\hline
\end{tabular}

of the Central American dust barrier. In Fig. 14, the longitudes of the Central American dust barrier $\left(80^{\circ}-90^{\circ} \mathrm{W}\right)$ correspond with increases in dust mass loss and northward transport. To quantify their relative contributions, we integrate the production-loss and north-south transport curves in Fig. 14 over the region of the Central American dust barrier. From this, we estimate that loss processes remove $1.67 \mathrm{Tg}$ of dust while the north-south dust flow transports $1.46 \mathrm{Tg}$ of dust out of the Central American dust barrier region during July 2007 (Table 1).

Based on these estimations, it is clear that both loss processes and atmospheric dynamics have a contribution to the Central American dust barrier. Of the two processes, dust loss from removal processes has a slightly greater contribution $(53 \%)$ to the Central American dust barrier than northward transport $(47 \%)$. 


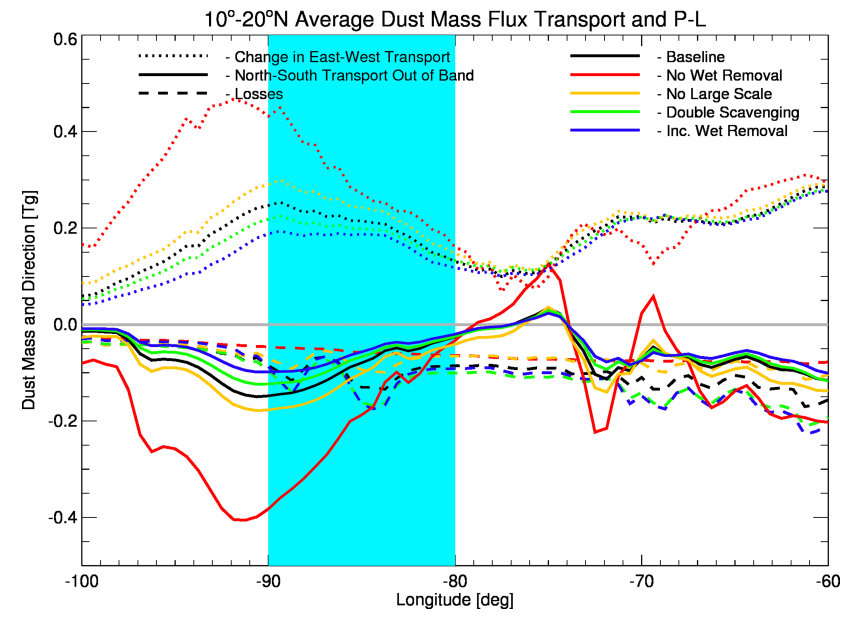

Fig. 14. $10^{\circ}-20^{\circ} \mathrm{N}$ July 2007 mass budget for our baseline, no wet removal, no large-scale scavenging, doubled scavenging, wet removal treated as other aerosols sensitivity tests. Shaded region indicates integration region for the Central American dust barrier.

\section{Discussion}

We have shown that loss processes have a greater contribution towards the Central American dust barrier than northward transport for July 2007. From Fig. 10, it is clear that wet removal by large scale and convective scavenging dominate the loss processes downwind of the Saharan source region between $10^{\circ}-20^{\circ} \mathrm{N}$ and serve as the major pathways for dust removal over the Caribbean. However, as discussed in Sect. 3, we suspect that our wet removal rates are not aggressive enough over the Caribbean and serves as the cause of our weaker representation of the Central American dust barrier in Fig. 2. To explore the controls of wet removal on our transported dust distributions, we perform additional simulations of July 2007 where we modify our parameterization of wet removal processes relative to our baseline simulation setup.

Table 1 presents a budget analysis for our baseline simulation, as well as the sensitivity analyses we will discuss here. Included are the dust mass removal by loss processes, north-south transport, and their contribution to the Central American dust barrier. Also shown are the $10^{\circ}-20^{\circ} \mathrm{N}$ net east-west mass transported across the planes at $80^{\circ} \mathrm{W}$ and $90^{\circ} \mathrm{W}$ and their difference. This difference, when combined with the north-south transport is the mass divergence and should approximately balance the mass removed by loss processes, with any residual attributable to the storage term in Eq. (1). Table 1 lists a dust mass barrier efficiency of the Central American dust barrier defined as the difference between the $10^{\circ}-20^{\circ} \mathrm{N}$ net east-west transported dust mass at $80^{\circ} \mathrm{W}$ (flow in) from that at $90^{\circ} \mathrm{W}$ (flow out) divided by the transported dust mass at $80^{\circ} \mathrm{W}$ (flow in). Additionally, after sampling consistently with MODIS-Terra, Table 1 lists a total AOT barrier efficiency and a coarse mode (dust plus

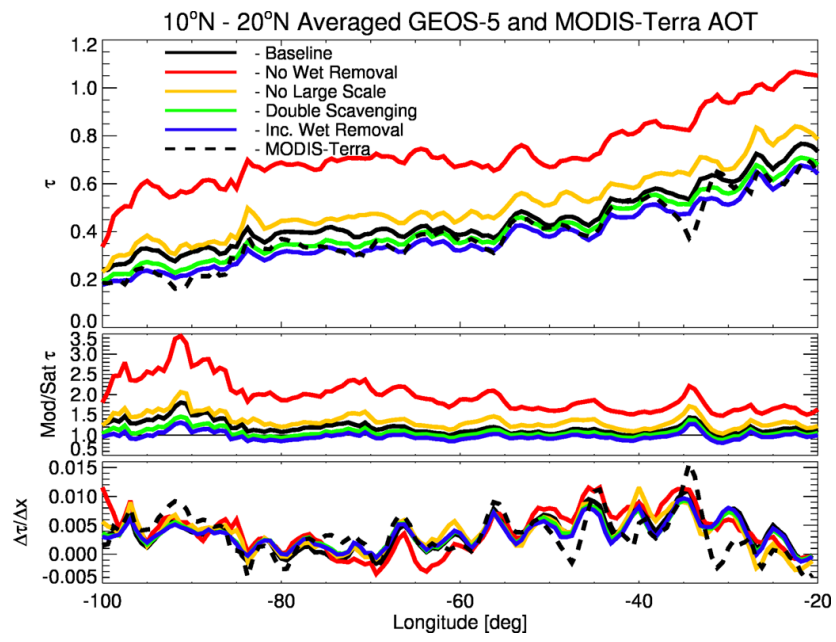

Fig. 15. $10^{\circ} \mathrm{N}-20^{\circ} \mathrm{N}$ averaged AOT, model to satellite AOT ratio, and AOT slope for MODIS-Terra and sampled baseline, no wet removal, no large-scale scavenging, doubled scavenging, and wet removal treated as other aerosols sensitivity tests. The thin black line indicates the one-to-one line for ratio plots.

sea salt) AOT efficiency that can be compared to the MODIS coarse mode AOT after averaging from $10^{\circ}-20^{\circ} \mathrm{N}$.

Our baseline simulation has a dust mass barrier efficiency of 0.36, meaning that the Central American dust barrier removes $36 \%$ of the dust mass between $80^{\circ} \mathrm{W}$ to $90^{\circ} \mathrm{W}$ (Table 1). Our baseline simulation has a total AOT barrier efficiency of 0.21 and a coarse AOT efficiency of 0.17. Comparisons to MODIS-Terra show that our removal rates are not aggressive enough, as MODIS-Terra has a total AOT barrier efficiency of 0.37 and coarse AOT barrier efficiency of 0.30 (Table 1).

As our model does not include a detailed representation of aerosol-cloud-precipitation interactions, we parameterize aerosol wet removal in terms of the model grid box convective updraft mass flux (for convective scavenging) and precipitation rate (for large scale wet removal). An efficiency factor is assigned to each aerosol species that represents its susceptibility to wet removal (i.e., its hygroscopicity) (Colarco et al., 2010). For dust we have assumed its wet removal efficiency is approximately half as efficiency as for hydrophilic carbonaceous and sulfate aerosols. In our first sensitivity test we double the dust convective scavenging efficiency so that it is equivalent to that for hydrophilic aerosols. In Fig. 14, we see that doubling the convective scavenging rate increases the mass of dust lost to removal while reducing the north-south and east-west dust flow. If we integrate along our longitudes of the Central American dust barrier, doubling the convective scavenging rate increases the loss contribution to $61 \%(1.90 \mathrm{Tg})$ and reduces the contribution by northward transport to $39 \%(1.24 \mathrm{Tg})$, increasing the mass barrier efficiency to 0.48 (Table 1). Figure 15 shows the MODISTerra sampled AOT from our baseline and sensitivity tests, 
the ratio of the MODIS-Terra and simulated AOT, and the slope of the AOT $(\Delta \tau / \Delta x)$. After doubling the convective scavenging rate, we see a reduction in the high AOT bias in the model and improvement in the slope of AOT as a function of longitude (Fig. 15). This corresponds with a significant improvement in the representation of the Central American dust barrier as the simulated AOT reduces from 0.34 at $80^{\circ} \mathrm{W}$ to 0.25 at $90^{\circ} \mathrm{W}$ (Fig. 15). This corresponds to greater AOT barrier efficiencies of the total (0.25) and coarse (0.21) representations of the Central American dust barrier.

We performed a second sensitivity test where in addition to doubling the dust convective scavenging rate, we increased the large-scale scavenging rate so that dust wet removal is treated the same as for hydrophilic aerosols. While this further increases the mass of dust lost to removal and reduces the north-south and east-west flow, we find that our simulated dust distributions are more sensitive to modifications to convective scavenging than large-scale scavenging in this region. However, the combined effect of increasing the large-scale and convective scavenging rates consistent with other aerosol types corresponds with an increased contribution from loss processes $(66 \%, 1.97 \mathrm{Tg})$, a reduced contribution $(34 \%, 1.02 \mathrm{Tg})$ from northward transport, and an increase in the barrier mass efficiency (0.52) of the Central American dust barrier (Table 1). Treating the wet removal of dust the same as other aerosols yields further improvement in the representation of the AOT magnitude and slope when compared to MODIS-Terra (Fig. 15). Over the region of the Central American dust barrier, the simulated AOT reduces from 0.31 at $80^{\circ} \mathrm{W}$ to 0.23 at $90^{\circ} \mathrm{W}$ (Fig. 15), corresponding with an improved total AOT barrier efficiency of 0.28 and a coarse AOT barrier efficiency of 0.22 (Table 1). Although still not as efficient as indicated by MODIS-Terra, this result suggests that the dust wet removal rates in GEOS-5 are too slow and treating the wet removal of dust in a fashion similar to other (more ostensibly hygroscopic) aerosol types yields better comparisons to observations in regions where wet removal is dominant. Because the representation of the dust barrier improves with increases to the wet removal rates, the contribution from loss processes to the Central American dust barrier is likely greater (66\%) than originally estimated from our baseline simulation (53\%).

We performed two additional sensitivity tests aimed at understanding if the Central American dust barrier exists when the effects of convective and large-scale scavenging are not simulated. In the first sensitivity test, we did not simulate wet removal from the large-scale scavenging of dust, leaving only convective scavenging as a source of wet removal. As shown in Fig. 14, large-scale scavenging over the Caribbean has a small effect on the dust load, as the northward and westward flows are slightly increased and losses are reduced when the effects of large-scale scavenging are not simulated. When we integrate over the longitudes of the Central American dust barrier, we see a shift in the relative significance of northward transport and loss. Northward flow transports
$1.85 \mathrm{Tg}$ of dust out of the region (59\% of the total removal) while dust losses remove $0.95 \mathrm{Tg}$ of dust $(41 \%$ of the total removal), corresponding with a barrier mass efficiency of 0.33 (Table 1). When the AOT is sampled consistent with MODIS-Terra, we see a small increase in the magnitude of the AOT and slope from the coast of North Africa $\left(20^{\circ} \mathrm{W}\right)$ to Central America $\left(80^{\circ} \mathrm{W}\right)$, but there is still evidence of a Central American dust barrier (Fig. 15). When the effects of large scale scavenging are not simulated, the total AOT efficiency and coarse AOT efficiency decrease to 0.19 and 0.16 , respectively (Table 1). This result is consistent with the simulations already discussed and suggests that large-scale convective scavenging has a small effect to the Central American dust barrier.

In a final sensitivity test, we performed a simulation where the effects of all wet removal (convective scavenging and large-scale scavenging) were not simulated. In Fig. 14, we see a large increase in the northward and westward dust flows and a significant reduction in the dust loss. Over the Central American dust barrier region, northward transport accounts for $78 \%$ (3.35 Tg) of dust removal from the atmospheric column, while loss processes account for $22 \%(1.28 \mathrm{Tg}$ ), corresponding with a mass barrier efficiency of 0.25 (Table 1). When compared to MODIS-Terra, we see a nearly constant increase in the AOT from the coast of North Africa $\left(20^{\circ} \mathrm{W}\right)$ to the beginning of the Caribbean $\left(60^{\circ} \mathrm{W}\right)$ (Fig. 15). However, over the Caribbean where convective scavenging has the largest contribution to the overall removal (Fig. 10), the model AOT relative to MODIS-Terra increases non-linearly (Fig. 15) and reduces the total and dust AOT barrier efficiency to 0.17 and 0.13 , respectively (Table 1). Finally, when all wet removal processes are not included, there is no evidence of the Central American dust barrier (Fig. 15). Therefore, we determine the Central American dust barrier could not exist without convective scavenging. In practice, however, the Central American dust barrier is the result of two processes working in tandem: (1) Loss processes significantly reducing the dust loading during transport and (2) Atmospheric dynamics redirecting the reduced dust flow northward near the Central American coastline.

\section{Conclusions}

We used the GEOS-5 model to understand the processes that contribute to the Central American dust barrier during transport from the Saharan source region to the Caribbean for the period of the NASA TC ${ }^{4}$ field campaign (July-August 2007). Near the Saharan source region, GEOS-5 has a similar plume shape to the MODIS observations, but our baseline simulation overestimated the AOT. Over the Caribbean, our GEOS5 AOT magnitude is comparable to MODIS, but provided a weaker representation of the Central American dust barrier. This result suggested that our loss processes be explored and possibly adjusted in future implementations of the model. 
In a series of sensitivity analyses with our model we explored the relationship between wet removal parameterization and transport in defining the Central American dust transport barrier. The best agreement between our model and the observations was obtained when dust wet removal was treated as we treat the removal of hydrophilic aerosol species. This result is supported by observations of unprocessed dust aerosols attracting water (Koretsky et al., 1997) to readily serve as cloud condensation nuclei $(\mathrm{CCN})(\mathrm{Ku}-$ mar et al., 2009). Our analysis shows that both wet removal and transport play a role in creating a semi-permeable barrier to dust transport across Central America into the Pacific. Of the two processes, for our best case simulation we find wet removal has a factor of two greater contribution toward defining the barrier than northward transport. Moreover, of the wet removal processes, the Central American dust barrier is more sensitive to removal by convective scavenging and is not evident when convective scavenging is not simulated.

Our results should be taken with a few caveats. First, our component analysis is valid for July 2007. While we have shown that the Central American dust barrier is a persistent feature in July (Fig. 2), we expect that the barrier will be somewhat sensitive to the variability of inter-annual meteorological conditions over the Central American region. Transported dust distributions will be sensitive to variability in Saharan dust emissions, AEJ strength, and InterTropical Convergence Zone (ITCZ) position. Prospero and Lamb (2003) showed that dust transported from the Sahara to the Caribbean is linked to Sahel precipitation from the previous year. Additionally, Pfister (2010) found that the La Nina conditions in 2007 caused an increase in westward flow and a significant reduction in Caribbean cold clouds and corresponding increase in Pacific cold clouds during the $\mathrm{TC}^{4}$ field campaign. This suggests that under normal conditions, transported dust would be more confined the Caribbean and the Central American dust barrier would have a greater presence. Inter-annual variability in the Central American dust barrier has implications for equatorial aquatic ecosystems located to the west of the Central American coastline. In this region, low phytoplankton growth inferred from chlorophyll concentration observations during July (Falkowski et al., 1998), suggest that the Central American dust barrier serves as a natural inhibitor of carbon sequestration in the Pacific. Additionally, we expect the Central American dust barrier to exist only in summer months. The AEJ forms during northern hemisphere summer and corresponds with peak dust transport from the Sahara to the Caribbean. Analysis of the MODIS-Terra 2000-2010 monthly climatology suggests that transported dust loadings are too low to see evidence of a Central American dust barrier during non-summer months. As part of our future endeavors, we plan to explore both intraannual and inter-annual variability of the Central American dust barrier, particularly the relative roles of transport and loss processes.
Another caveat is that we did not explore the role of dry removal processes, though similar to wet removal, dry removal rates are not well constrained by data. Additionally, we neglected compensating effects in removal rates when removal processes were modified in the sensitivity studies. However, by mass, dry removal becomes less important with distance from the source region. Offline analysis confirmed this, as dry removal rates from our no wet removal simulation increased by a factor of 1.3 when compared to our baseline simulation over the region of the Central American dust barrier.

One final caveat is that the strength of our results is limited by how well transport and loss processes are represented in the model. The effect of transport on the Central American dust barrier will be sensitive to the accuracy of the meteorology used to drive transport (i.e. MERRA reanalyses), as well as the internal dynamics of the model that advect dust in-between analyses. Therefore, the role of transport towards the Central American dust barrier may be different in another global aerosol transport model. Our analysis also relies heavily on the ability of the model to provide a realistic representation of convection, which subsequently influences wet removal over the Caribbean. Because wet removal rates are not typically measured in the field, it is difficult to determine whether our parameterization of wet removal is accurate and therefore we are limited to relying on proxies, such as column AOT. As previously discussed, our baseline simulation provided a weak representation of the Central American dust barrier when compared to MODIS-Terra, suggesting that our wet removal rates were too relaxed in the model (Fig. 2). However, when compared to the GPCP observations, the July 2007 mean GEOS-5 precipitation was slightly greater over most of the Caribbean (Fig. 7). These results suggest that the connection between wet removal and precipitation should be strengthened in GEOS-5, in particular that our simulation which best captured this dust barrier was the one that treated dust the same as hygroscopic aerosol species with respect to wet removal processes, suggesting that the best representation of dust in our model is one which allows that dust has mixed or been processed so as to be more hydrophilic.

Acknowledgements. We would like to thank Judd Welton for his assistance with CALIOP data. This work was funded by the NASA Modeling, Analysis, and Prediction program and a NASA Earth System Science Fellowship.

Edited by: N. Riemer

\section{References}

Adler, R. F., Huffman, G. J., Chang, A., Ferraro, R., Xie, P.-P., Janowiak, J., Rudolf, B., Schneider, U., Curtis, S., Bolvin, D., Gruber, A., Susskind, J., Arkin, P., and Nelkin, E.: The Version2 Global Precipitation Climatology Project (GPCP) Monthly 
Precipitation Analysis (1979-Present), J. Hydrometeorol., 4, 1147-1167, 2003.

Brown, R. A.: Fluid Mechanics of the Atmosphere, Academic Press Inc., San Diego, CA, 1991.

Carlson, T. N. and Prospero, J. M.: The large-scale movement of Saharan air outbreaks over the northern equatorial Atlantic, J. Appl. Meteorol., 11, 283-297, 1972.

Chin, M., Ginoux, P., Kinne, S., Torres, O., Holben, B., N., Duncan, B. N., Martin, R. V., Logan, J. A., Higurashi, A., and Nakajima, T: Tropospheric aerosol optical thickness from the GOCART model and comparisons with satellite and sun photometer measurements, J. Atmos. Sci., 59(3), 461-483, 2002.

Colarco, P. R., Toon, O.B., Reid, J. S., Livingston, J. M., Russell, P. B., Redemann J., Schmid, B., Maring, H. B., Savoie, D., Welton, E. J., Campbell, J. R., Holben, B. N., and Levy, R.: Saharan dust transport to the Caribbean during PRIDE: 2. Transport, vertical profiles, and deposition in simulations of in situ and remote sensing observations, J. Geophys. Res., 108(D19), 8590, doi:10.1029/2002JD002659, 2003.

Colarco, P. R., da Silva, A., Chin, M., and Diehl, T.: Online simulations of global aerosol distributions in the NASA GEOS-4 model and comparisons to satellite and groundbased aerosol optical depth, J. Geophys. Res., 115, D14207, doi:10.1029/2009JD012820, 2010.

Cook, K. H.: Generation of the African Easterly jet and its role in determining West African precipitation, J. Climate, 12, 11651184, 1999.

DeMott, P. J., Sassen, K., Baumgardner, D., Rogers, D. C., Brooks, S. D., Prenni, A. J., and Kreidenweis, S. M.: African dust aerosols as atmospheric ice nuclei, Geophys. Res. Lett., 30(14), 1732, doi:10.1029/2003GL017410, 2003.

Desboeufs, K. V., Losno, R., and Colin, J.: Factors influencing aerosol solubility during cloud processes, Atmos. Environ., 35, 3529-3527, doi:10.1016/S1352-2310(00)00472-6, 2001.

Dubovik, O. and King, M. D.: A flexible inversion algorithm for retrieval of aerosol optical properties from sun and sky radiance measurements, J. Geophys. Res., 105(D16), 20673-20696, 2000.

Duce, R. A. and Tindale, N. W: Atmospheric transport of iron and its deposition in the ocean, Limnol. Oceanogr., 36, 1715-1726, 1991.

Dunion, J. P. and Velden, C. S.: The impact of the Saharan air layer on Atlantic tropical cyclone activity, Bull. Am. Meteorol. Soc., 85(3), 353-365, 2004.

Falkowski, P. G., Barber, R. T., and Smetacek, V.: Biogeochemical controls and feedbacks on primary production, Science, 281, 200-206, 1998.

Ginoux, P., Chin, M., Tegen, I., Prospero, J. M., Holben, B. N., Dubovik, O., and Lin, S.-J.: Sources and distributions of dust aerosols simulated with the GOCART model, J. Geophys. Res., 106(D17), 20255-20273, 2001.

Hand, J., Mahowald, N., Chen, Y., Siefert, R., Lou, C., Subramaniam, A., and Fung, I.: Estimates of soluble iron from observations and a global mineral aerosol model: Biogeochemical implications, J. Geophys. Res., 109, D17205, doi:10.1029/2004JD004574, 2004.

Haywood, J., Francis, P, Osborne, S., Glew, M., Loeb, N., Highwood, E., Tanré, D., Myhre, G., Formenti, P., and Hirst, E.: Radiative properties and direct radiative effect of Saharan dust measured by the C-130 aircraft during SHADE: 1. Solar spectrum,
J. Geophys. Res., 108(D18), 8577, doi:10.1029/2002JD002687, 2003.

Hill, C., DeLuca, C., Balaji, V., Suarez, M., da Silva, A., and the ESMF Joint Specification Team: The Architecture of the Earth System Modeling Framework, Comput. Sci. Eng., 6, 1-6, 2004.

Huffman, G. J., Adler, R. F., Morrissey, M., Bolvin, D., Curtis, S., Joyce, R., McGavock, B., and Susskind, J., Huffman, G. J., Adler, R. F., Morrissey, M., Bolvin, D., Curtis, S., Joyce, R., McGavock, B., and Susskin, J: Global Precipitation at One-Degree Daily Resolution from Multisatellite Observations. J. Hydrometeorol, 2, 36-50, 2001.

Jickells, T. D., An, Z. S., Andersen, K. K., Baker, A. R., Bergametti, G., Brooks, N., Cao, J. J., Boyd, P. W., Duce, R. A., Hunter, K. A., Kawahata, H., Kubilay, N., LaRoche, J., Liss, P. S., Mahowald, N., Prospero, J. M., Rigwell, A. J., Tegen, I., and Torres, R.: Global iron connections between desert dust, ocean biogeochemistry, and climate, Science, 308(5718), 67-71, 2005.

Karyampudi, V. M., Palm, S. P., Reagan, J. A., Fang, H., Grant, W. B., Hoff, R. M., Moulin, C., Pierce, H. F., Torres, O., Browell, E. V., and Melfi, S. H.: Validation of the Saharan dust plume conceptual model using lidar, Meteosat, and ECMWF data, Bull. Am. Meteorol. Soc., 80, 1045-1075, 1999.

Kaufman, Y. J., Koren, I., Remer, L. A., Tanré, D., Ginoux, P., and Fan, S.: Dust transport and deposition observed from the Terra-Moderate Resolution Imaging Spectroradiometer (MODIS) spacecraft over the Atlantic Ocean, J. Geophys. Res., 110, D10S12, doi:10.1029/2003JD004436, 2005.

Kieber, R. J., Willey, J. D, and Avery, G. B.,: Temporal variability of rainwater iron speciation at the Bermuda Atlantic Time Series Station, J. Geophys. Res., 108(C8), 3277, doi:10.1029/2001JC001031, 2003.

Koretsky, C., Sverjensky, D., Salisbury, J., and D'Aria, D.: Detection of surface hydroxyl species on quartz, gamm-alumina and feldspar using diffuse reflectance infrared spectroscopy, Geochim. Cosmochim. Acta, 61, 2193-2210, 1997.

Lau, W. K. M. and Kim, K.-M.: How Nature Foiled the 2006 Hurricane Forecasts, Eos Trans. AGU, 88(9), doi:10.1029/2007EO090002, 2007.

Levy, R. C., Remer, L.A., Kleidman, R. G., Mattoo, S., Ichoku, C., Kahn, R., and Eck, T. F.: Global evaluation of the Collection 5 MODIS dark-target aerosol products over land, Atmos. Chem. Phys., 10, 10399-10420, doi:10.5194/acp-10-10399-2010, 2010.

Luo, C., Mahowald, N. M., and del Corral, J.: Sensitivity study of meteorological parameters on mineral aerosol mobilization, transport, and distribution, J. Geophys. Res., 108(D15), 4447, doi:10.1029/2003JD003483, 2003.

Mahowald, N. M.: Anthropocene changes desert area: Sensitivity to climate model predictions, Geophys. Res. Lett., 34, L18817, doi:10.1029/2007GL030472, 2007.

Mahowald, N. M., Baker, A. R., Bergametti, G., Brooks, N., Duce, R. A., Jickells, T. J., Kubilay, N., Prospero, J. M., and Tegen, I.: Atmospheric global dust cycle and iron inputs to the ocean, Global Biogeochem. Cy., 19, GB4025, doi:10.1029/2004GB002402, 2005.

McGill, M. J., Hlavka, D. L., Hart, W. D., Scott, V. S., Spinhirne, J. D, and Schmid, B.: The cloud physics lidar: Instrument description and initial measurement results, Appl. Opt., 41, 3725-3734, 2002.

McGill, M. J., Hlavka, D. L, Hart, W. D., Welton, E. J., and 
Campbell, J. R.: Airborne lidar measurements of aerosol optical properties during SAFARI-2000, J. Geophys. Res., 108(D13), 8493, doi:10.1029/2002JD002370, 2003.

McGill, M. J., Li, L., Hart, W. D., Heymsfield, G. M., Hlavka, D. L., P. E., Tian, L., Vaughan, M. A., and Winker, D. M.: Combined lidar-radar remote sensing: Initial results from CRYSTAL-FACE, J. Geophys. Res., 109, D07203, doi:10.1029/2003JD004030, 2004.

Nowottnick, E., Colarco, P., Ferrare, R., Chen, G., Ismail, S., Anderson, B., and Browell, E.: Online simulations of mineral dust aerosol distributions: Comparison to NAMMA observations and sensitivity to dust emission parameterization, J. Geophys. Res., 115, D03202, doi:10.1029/2009JD012692, 2010.

Pawson, S., Stolarski, R. S., Douglass, A. R., Newman, P. A., Nielsen, J. E., Frith, S. M., and Gupta, M. L.: Goddard Earth Observing System chemistry-climate model simulations of stratospheric ozone-temperature coupling between 1950 and 2005, J. Geophys. Res., 113, D12103, doi:10.1029/2007JD009511, 2008.

Petit, R. H., Legrand, M, Jankowiak, J., Molinié, J., Asselin de Beauville, C., Marion, G., and Mansot, J. L.: Transport of Saharan dust over the Caribbean Islands: Study of an event, J. Geophys. Res., 110, D18S09, doi:10.1029/2004JD004748, 2005.

Pfister, L., Selkirk, H. B., Starr, D. O., Rosenlof, K., and Newman P. A.: A meteorological overview of the TC4 mission, J. Geophys. Res., 115, D00J12, doi:10.1029/2009JD013316, 2010.

Prospero, J. and Lamb, P.: African droughts and dust transport to the Caribbean: climate change implications, Science, 302, 10241027, 2003.

Prospero, J. M., Ginoux, P., Torres, O., Nicholson, S. E., and Gill, T. E.: Environmental characterization of global sources of atmospheric soil dust identified with the Nimbus 7 Total Ozone Mapping Spectrometer (TOMS) absorbing aerosol product, Rev. Geophys., 40(1), 1002, doi:10.1029/2000RG000095, 2002.

Remer, L. A., Kaufman, Y. J., Tanré, D., Mattoo, S., Chu, D. A., Martins, J. V., Li, R.-R., Ichoku, C., Levy, R. C., Kleidman, R. G., Eck, T. F., Vermote, E., and Holben, B. N.: The MODIS aerosol algorithm, products, and validation, J. Atmos. Sci., 62(4), 947-973, 2005.

Rienecker, M. M., Suarez, M. J., Todling, R., Bacmeister, J., Takacs, L., Liu, H.-C., Gu, W., Sienkiewicz, M., Koster, R. D., Gelaro, R., Stajner, I., and Nielsen, J. E.: The GEOS- 5 Data Assimilation System-Documentation of Versions 5.0.1, 5.1.0, and 5.2.0., Technical Report Series on Global Modeling and Data Assimilation, 104606, 27, 2008.
Rienecker, M., Suarez, M. J., Gelaro, R., Todling, R., Bacmeister, J., Liu, E., Bosilovich, M. G., Schubert, S. D., Takacs, L., Kim, G.-K., Bloom, S., Chen, J., Collins, D., Conaty, A., da Silva, A., Gu, W., Joiner, J., Koster, R. D., Lucchesi, R., Molod, A., Owens, T., Pawson, S., Pegion, P., Redder, C. R., Reichle, R., Robertson, F. R., Ruddick, A. G., Sienkiewicz, M., and Woollen, J.: MERRA - NASA's Modern-Era Retrospective Analysis for Research and Applications, J. Climate, 24, 3624-3648, doi:10.1175/JCLI-D-11-00015.1

Rosenfeld, D., Rudich, Y., and Lahav, R.: Desert dust suppressing precipication: A possible desertification loop, P. Natl. Acad. Sci., 98(11), 5975-5980, 2001.

Sokolik, I. N. and Toon, O. B.: Direct radiative forcing by anthropogenic airborne mineral aerosols, Nature, 381(6584), 681-683, 1996.

Tanaka, T. Y. and Chiba, M.: Global simulation of dust aerosol with a chemical transport model, MASINGAR, J. Meteorol. Soc. Jpn., 83A, 255-278, 2005.

Toon, O. B., Starr, D. O., Jensen, E. J., Newman, P. A., Platnick, S., Schoeberl, M. R., Wennberg, P. O., Wofsy, S. C., Kurylo, M. J., Maring, H., Jucks, K. W., Craig, M. S., Vasques, M. F., Pfister, L., Rosenlof, K. H., Selkirk, H. B., Colarco, P. R., Kawa, S. R., Mace, G. G., Minnis, P., and Pickering, K. E.: Planning, implementation, and first results of the Tropical Composition, Cloud and Climate Coupling Experiment (TC4), J. Geophys. Res., 115, D00J04, doi:10.1029/2009JD013073, 2010.

Vaughan, M. A. , Young, S., Winker, D., Powell, K., Omar, A., Liu, Z., Hu, Y., and Hostetler, C.: Fully automated analysis of space-based lidar data: An overview of the CALIPSO retrieval algorithms and data products, Proc. SPIE Int. Soc. Opt. Eng., 5575, 16-30, 2005.

Winckler, G., Anderson, R. F., Fleisher, M. Q., McGee, D., and Mahowald, N.: Covariant glacial-interglacial dust fluxes in the equatorial Pacific and Antarctica, Science, 320(5872), 93-96, 2008.

Zhu, X. R., Prospero, J. M., and Millero, F. J.: Diel variability of soluble $\mathrm{Fe}(\mathrm{II})$ and soluble total Fe in North African dust in the trade winds at Barbados, J. Geophys. Res., 102(D17), 21,29721,305, doi:10.1029/97JD01313, 1997.

Zhu, A., Ramanathan, V., Li, F., and Kim, D.: Dust plumes over the Pacific, Indian, and Atlantic oceans: Climatology and radiative impact, J. Geophys. Res., 112(D16), D16208, doi:10.1029/2007JD008427, 2007. 